monografico: antropología del turismo, texto 9: 109-143.

\title{
MEMORIA DE UN ARQUITECTO: ALDO ROSSI. \\ Proyecto vital e itinerario científico (estudio analítico de una autobiografía)
}

\author{
Isusko VIVAS ZIARRUSTA; Amaia LEKERIKABEASKOA GAZTAÑAGA \\ Universidad del País Vasco UPV/EHU. \\ isusko.vivas@ehu.es, amaia.lekerikabeaskoa@ehu.es
}

\begin{abstract}
REPORT OF AN ARCHITECT: ALDO ROSSI. Vital project and scientific itinerary (analytical study of an autobiography)
\end{abstract}

Resumen: Además de las aportaciones relevantes del autor que constituyen un recorrido profesional y vital, se destaca tanto el 'itinerario personal' como el 'proyecto científico' del arquitecto, ya que su legado no encuentra distinción entre lo escrupulosamente profesional y esa identidad personal 'única e intransferible', como de hecho se pone de manifiesto en el esfuerzo autobiográfico de uno de los últimos arquitectos 'revolucionarios', de los que aún opinaban que 'para cambiar el mundo, habían de cambiar las ciudades que habitamos...' a veces dificultosamente', tal y como pronosticaron los iluministas y recogieron los modernos. Quizás sin pretenderlo tenga A. Rossi, en este sentido, más en común de lo deseado con los arquitectos 'modernos' -en mayúsculas- (tan denostados en parte por él), y también con aquellos otros 'iluminados' -(Boullée, Ledoux, Lequeu...)- en tanto que 'revolucionarios' arquitectónicamente hablando, todos ellos, e igualmente revolucionarios algunos en sus ideologías al menos teóricamente, si bien con matices propios de la época.

Abstract: In addition to the important contributions of the author to provide a professional and life journey, highlights both the 'personal journey' as the 'science project' architect, and his legacy is no distinction between the strictly professional and that only personal 'identity and transferable ', as indeed is evident in the autobiographical effort of one of the last architects' revolutionary', of those who still believed that 'to change the world, they had to change the cities we live ...' sometimes painfully ', as predicted the Enlightenment and collected modern. Perhaps unintentionally have A. Rossi, in this sense, more in common than desired 'modern' architects-in-capital (as reviled in part by him), and also with those other 'enlightened' (Boullée, Ledoux , Lequeu ...) - while 'revolutionary' architecturally speaking, all of them, and also some in their revolutionary ideologies at least theoretically, although with nuances of the time.

Palabras clave: Aldo Rossi; Arquitecto; Autobiografía (Científica); Itinerario profesional; Estudio analítico Aldo Rossi; Architect; Autobiography (scientific); Professional itinerary; Analytical study 


\section{Primera parte. Prólogo introductorio}

"El olvido está lleno de memoria..." (Mario Benedetti).

Este análisis autobiográfico que se prologa mediante estas notas preliminares, se ha subtitulado así mismo con la leyenda que expresa una idea dual: 'proyecto personal e itinerario científico', algo así como un trampantojo óptico, un 'cis-trans' literario que en la virtualidad del espejo biográfico una personalidad se 'refleja', oscura, difusa, clara o transparente según asoma la memoria, o el olvido que en la unificación de los opuestos es también 'memoria'. Así es como se complementan ambas partes diferenciadas del encabezamiento titular, puesto que todo proyecto arquitectónico es de algún modo concebido como 'proyecto personal' propio, si consideramos este punto de partida que continuamente transpira de las palabras de Aldo Rossi.

Se destaca tanto el 'itinerario personal' como el 'proyecto científico' del arquitecto, ya que su legado no encuentra distinción entre lo escrupulosamente profesional y esa identidad personal 'única e intransferible', como de hecho se pone de manifiesto en el esfuerzo autobiográfico de uno de los últimos arquitectos 'revolucionarios', de los que aún opinaban que 'para cambiar el mundo, habían de cambiar las ciudades que habitamos...' a veces dificultosamente', tal y como pronosticaron los iluministas y recogieron los modernos. Quizás sin pretenderlo tenga A. Rossi, en este sentido, más en común de lo deseado con los arquitectos 'modernos' -en mayúsculas- (tan denostados en parte por él), y también con aquellos otros 'iluminados' -(Boullée, Ledoux, Lequeu...)- en tanto que 'revolucionarios' arquitectónicamente hablando todos ellos e igualmente revolucionarios en sus ideologías al menos teóricamente, si bien con matices propios de la época.

Es por lo que a A. Rossi lo podemos emparentar en la senda que recoge las herencias de arquitectos más teóricos como su homónimo inmediatamente anterior en el panorama americano (alrededor de 1950): Kevin Lynch, especialmente el austríaco Adolf Loos en el instante finisecular entre el siglo XIX y el XX, sin olvidarnos tampoco de figuras como Sr. John Soane inmersos en la Inglaterra victoriana y romántica que comienza a desprenderse de sus pasados lastres y 'revivalismos' estilísticos, o más tempranamente, los arquitectos neoclásicos utópicos -teóricos y visionarios-, los primeros 'racionalistas' del s. XVIII; Boullée, Ledoux, Lequeu,... sobre todo en la Francia pre y postrevolucionaria. Sin embargo en nuestra historia más contemporánea Rossi ha estado en la onda de arquitectos como Cesar Portela (con el que incluso colaboró en el diseño del continente edilicio para el Museo del Mar de Galicia en la Ría de Vigo, durante la década de 1990). Por ahí andan también, cerca que lejos, profesionales no menos loables y estimables como Alvaro Siza, Alvar Aalto o si se apura Renzo Piano y L. Peña Gantxegi, seguidores de esta tradición. Tradición que, huyendo de la arquitectura tecnócrata grandilocuente de los 'arquitectos emblema' y construcciones paradigmáticas 'neomonumentales' que aquí no procede comentar, hay que integrarla en cambio en el marco de la regeneración urbanística de entornos degradados por la acción destructora del tiempo malgastado y las economías malversadas, o el declive industrial en zonas de actividades productivas obsoletas, cuando no la rehabilitación de ciudades asoladas por las contiendas bélicas (prueba de ello será la participación de Rossi en el IBA de Berlín hacia la mitad de los años ochenta), con las consiguientes teorías que de ello se derivan sobre la ciudad que ha de recuperar tanto como preservar la memoria histórica, desde una visión 'culturalista' -sociocultural- de la arquitectura enfocada hacia el urbanismo, como en nuestro contexto trata de explicarlo Javier Cenicacelaya para que se pueda comprender de una forma meridianamente inteligible.

Arquitectos que prestan suma atención a la configuración histórica e identitaria de la ciudad a expensas del planeamiento y/o planificación urbana en contrapunto al proyecto puntual descontextualizado, de cara a la consecución de un paisaje construido en sintonía 
con las señas de identidad de los 'lugares' -el 'locus' para A. Rossi-, una arquitectura que tiene por objeto la consecución y modelación del 'lugar antropológico de la memoria' y la heterodoxia, y no los espacios del anonimato y la indeterminación; los 'no-lugares' de la 'mayoría silenciosa' (Baudrillard), diversificados para el olvido y la homogeneidad bajo los postulados de la 'sobremodernidad' en Marc Augé. La ciudad se erige en escenario y paisaje para la arquitectura. Arquitectura que se sobrepone al paisaje como advierte José Laborda (-otro arquitecto teórico-), y sobre lo cual se gesta la 'cultura urbana'. Francisco Umbral decía que "entre mí y el paisaje estaba la cultura" (citado en Marina, 1997: 49), tanto como entre el paisaje primigenio y la cultura, se encuentra ya irremediablemente la arquitectura.

Si como asegura José $\mathrm{M}^{\mathrm{a}}$ Pozuelo el género autobiográfico nace en la convergencia intelectual entre la invención del 'yo' y la justificación externa de ese 'yo' identitario construido, en Aldo Rossi llega al extremo de que la 'identidad personal' casi la 'construye' la propia arquitectura en una unión simbiótica entre vida y arquitectura que cuyos lazos trazados en la autobiografía son forzosamente inseparables, teniendo muy presente que la escritura autobiográfica consiste "en contar cómo se ha llegado a ser el que se es. No se trata de una mera narración retrospectiva que el autor del texto hace de su pasado". Esto nos indica que no puede ser simple reconstrucción de un tiempo más o menos ptretérito:

"El objetivo no es la selección y el recuento de los hechos que vivió directa o indirectamente. Lo que importa a quien narra la propia vida es configurar su identidad, crearle un horizonte al presente plano, construirse para sí mismo y para otros en toda su complejidad humana. Una autobiografía resulta así más el encuentro con la memoria personal, la indagación en la memoria íntima, que la recuperación del pasado. Por eso no sería exagerado considerar a la memoria como el eje vertebrador de la autobiografía" (Fernández Prieto, 1997: 68). ${ }^{1}$

Estas ideas nos sitúan en el concepto de autobiografía como ejercicio mental en el que esa 'memoria única e intransferible' que se decía al inicio, en la que poco importan los demás, si es que 'existen' o 'aparecen' (-se 'recuerdan'-); es memoria representada, 'tematizada’ y en última instancia 'figura' (Fernández Prieto, 1997: 69).

Con el análisis de la autobiografía científica -o más bien pseudocientífica- de Aldo Rossi vamos a inmiscuirnos en esas 'claves interpretativas de la memoria' y 'espacios para la memoria', si tenemos en cuenta que un mundo desposeído de memoria es 'es un mundo del presente' como decía Alan Lightman; esto es, un mundo del 'eterno presente' para Jean Baudrillard. Espacios que, en ocasiones, pueden ser quasi-arquitectónicos en la acepción de Francis Yates; a modo de 'intersticios' para el ejercicio de ciertas 'memorias', rememorando que incluso en los espacios construidos de los templos clásicos o preclásicos se reservaban determinadas 'salas' para funciones de diálogo, conversación, discusión y estructuración en la narración de un discurso reflexivo. Intentaremos identificar las 'memorias' y los 'olvidos' con una metodología que atienda a diversas 'pautas para el recuerdo' como hitos que 'se asemejan a los mojones que aparecen a lo largo de la 'senda', del camino (vivencias significativas a nivel individual -'anthropos'-, elementos desencadenantes del recuerdo que aparecen con nitidez), intersecciones o encrucijadas, articulaciones e intersticios, esos 'resquicios de luz en la oscura y lúgubre profundidad de la gambara’ como propone la antropólogo Ma

\footnotetext{
1 “El género de las memorias, en cambio, se orienta preferentemente a la reconstrucción del pasado; el memorialista pretende dar testimonio de los acontecimientos en los que participó, de las personas a las que conoció, y explicar o justificar su conducta en una circunstancia histórica relevante; de ahí el que se apoye en cartas, fotografías y documentos de diversa índole, que precise las fechas, que describa con cuidado los escenarios, es decir, que utilice todos los elementos que contribuyan a objetivar la memoria personal, a desprivatizarla, a incorporarla a la memoria ciolectiva. Sin duda en la práctica de los textos ambas tendencias, la introspectiva y la testimonial, se alternan y se complementan”. Ibíd.
} 
Teresa del Valle, o "la niebla que penetra [...] como algo imprevisible, que modifica y altera, como luz y sombra..." (Rossi, 1984: 10). Nos encontramos así con la 'fuerza del poder evocador', fuerza simbólica y 'evocadora' del pasado que cuando toma imagen se instituye en monumento conmemorativo.

No se pretende, sin embargo, concluir la redacción de estas líneas introductorias sin hacer mención a los elementos que se acaban de identificar para el estudio metodológico de la autobiografía: hitos (mojones), intersecciones, articulaciones e intersticios, en relación con las figuras similares que el arquitecto Kevin Lynch (al cual, por cierto, Aldo Rossi no hace ninguna alusión en la 'autobiografía...' aunque resulte evidente la lectura y asimilación de sus presupuestos teóricos), ${ }^{2}$ propone para la investigación y el escrutinio de los fenómenos urbanos que acontecen en la ciudad, sobre todo por las continuas referencias que se dirigen hacia el plano de la memoria identitaria y para encauzar este estudio en una línea que sintonice con el propio modo de entender los parámetros culturales y personales de A. Rossi, siempre concatenados con sus apreciaciones acerca de la ciudad y la arquitectura estructura y significado. Por 'identificación' se entiende su distinción respecto a otras ciudades, mientras que por identidad. Desde esta perspectiva 'la imagen de la ciudad' según Kevin Lynch ${ }^{3}$ contiene tres partes: identidad, se entiende la unicidad de esa urbe. Por estructura la relación espacial reglamentada de un núcleo urbano. Por significado las connotaciones prácticas o emotivas de una ciudad para un observador. Son cinco los elementos que nos permiten estudiar la imagen de una ciudad: sendas (conductos, calles, líneas de tránsito, canales o vías férreas que tienen una importancia estructurante). Las intersecciones de las sendas adquieren además gran importancia como 'puntos de decisión' -o 'indecisión'(como en las autobiografías...). Constituyen así encrucijadas que recuerdan en cierto sentido su relevancia en otras épocas, como cruces de caminos y lugares en donde incluso surgen asentamientos humanos. Otros elementos que K. Lynch evidencia son los bordes (rupturas lineales de la continuidad. Playas, cruces de ferrocarril, muros), barrios, nodos -'puntos conceptuales de sujeción de las ciudades', su presencia puede hacerse notar por un hito simbólico- (confluencias, 'permanencias' en la ciudad a nivel colectivo -'etnos'-) y mojones. La relevancia y valor como mojón se incrementa además a medida que se 'adhiere a un objeto una historia' (al igual que en la autobiografía un 'personaje' forja su individual 'historia', su identidad y su 'memoria'), coincidiendo su importancia simbólica y su importancia visual como hito o monumento, de modo que, por lo regular los elementos se superponen y se interpenetran Este es básicamente el alfabeto urbano que Lynch propone para leer la ciudad (como el 'alfabeto' que antes describíamos para 'leer' la autobiografía). Todos los elementos actúan conjuntamente ante un observador que podría agruparlos bajo un concepto de 'complejo' o sistema, en donde las partes se encuentran relacionadas entre sí, de tal manera que, si se organiza el medio de forma visible para su nítida identificación, puede comenzarse

\footnotetext{
2 Un autor que sí cita, sin embargo, a K. Lynch es José Luque Valdivia, que analizando cuestiones sobre todo de imagen y memoria colectiva como antes veíamos, expresa cómo K. Lynch proporciona los cauces necesarios para comprender el lugar, el 'locus' aludido por Aldo Rossi, como una suerte de espacio 'fenomenológico y colectivo' al mismo tiempo, superando así un 'entendimiento del lugar como una realidad ajena' al ser humano. Para este investigador, las experiencias tanto de Kevin Lynch como de Gyorgy Kepes se relacionan con las teorías de la percepción inducidas por las Gestalttheory y Gestaltpsicology, teorías aplicadas no obstante a la fenomenología de las ciudades, transfiriéndose la atención desde la arquitectura (desde el objeto) hacia el fondo, constituido por el paisaje urbano como contexto arquitectónico y 'natural'. Esta inversión de esquemas y conceptos es bastante significativa para comprender el desarrollo que los espacios urbanos adquieren a partir de dichas premisas, pues esos espacios serán los lugares en los que se asentarán los elementos urbanos, los monumentos escultóricos y las manifestaciones de arte público en general.

3 Las reflexiones de $\mathrm{K}$. Lynch se centran fundamentalmente en los modelos de ciudad americana (preparando sus estudios en especial para los casos de Boston, Los Angeles o Jersey city). No obstante algunos de los resultados pueden también ser extensibles a otros modelos de ciudad y ordenación urbana.
} 
a atribuirle significados e interconexiones que proporcionan identidad de 'lugar'.

A partir de estos elementos puede dividirse el espacio y organizarse alrededor de una serie de puntos focales, partido en regiones nominadas mediante rutas que permanecen en la memoria. K. Lynch define así el término de la 'imaginabilidad', como la "cualidad de un objeto físico que le da una gran probabilidad de suscitar una imagen vigorosa en cualquier observador de que se trate" (Lynch, 1984: 19). Una imagen que se puede fortalecer en todo caso por medio de artilugios o 'artificios simbólicos', (el monumento por ejemplo) remodelando el contorno o mediante la reeducación de un potencial perceptor. En este sentido se consolida una determinada 'imagen pública de cada ciudad' (la autobiografía configura una 'imagen pública' más o menos intimista del individuo 'emisor' de la memoria) como superposición de un sin fin de imágenes individuales, "o quizás lo que hay es una serie de imágenes públicas, cada una de las cuales es mantenida por un número considerable de ciudadanos [receptores, 'lectores'. En todo caso] hay otras influencias que actúan sobre la

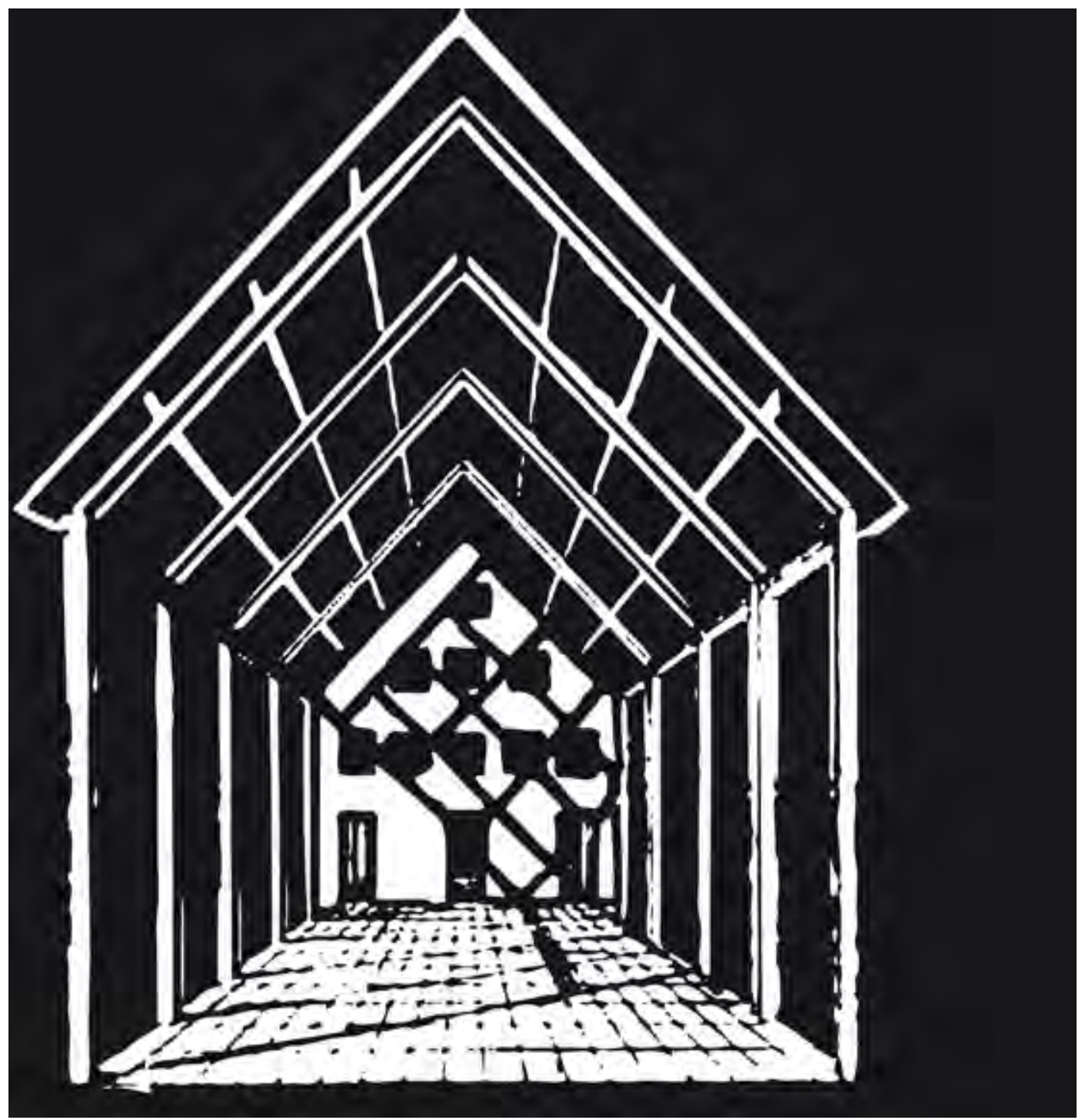

Figura. 1. Residencia de estudiantes de Chieti. Aldo Rossi, 1976 
imaginabilidad, como el significado social de una zona, su función, su historia e incluso su nombre [topónimo]". (Lynch, 1984: 61). Finalmente se quiere cerrar este apartado con una significativa cita de Lynch que alude y sintetiza muchas de las cuestiones que hasta ahora se han pretendido evidenciar:

"Es muy cierto que necesitamos un medio que no sólo esté bien organizado sino que asimismo sea poético y simbólico. El medio debe hablar de los individuos y su compleja sociedad, de sus aspiraciones y su tradición histórica, del marco natural y de las funciones y los movimientos complejos del mundo urbano. Pero la claridad de la estructura y la vividez de la identidad son los primeros pasos para el desarrollo de símbolos vigorosos. Al aparecer como un 'lugar' notable y consistente, la ciudad podría proporcionar un terreno para la acumulación y la organización de estos significados y asociaciones. En sí mismo, tal sentido del lugar realza todas las actividades humanas que se desarrollan y fomentan la formación de una memoria" (Lynch, 1984: 146-147).

\section{Segunda parte. Estudio analítico de una autobiografía}

“...Y cuando, en invierno, las grandes playas quedaban vacías, todavía conservaban ese carácter de tierras movedizas de una ciudad provisional a la que una calle paralela al mar separaba de la otra ciudad. Pero aquella sería siempre la ciudad de los encuentros, como el muelle, como todo lo que está entre la tierra y el agua, o entre la tierra y el cielo" (Aldo Rossi).

Iniciamos este estudio analítico de la Autobiografía científica ${ }^{4}$ de Aldo Rossi considerando una cuestión ya anunciada repetidamente con anterioridad, indicativa de la interconexión que a lo largo de su trayectoria personal y profesional se entrevé en la discusión y mezcla de sus proyectos y principales influencias artísticas o literarias, con su propia historia tal y como introduce Kurt Foster en el prólogo para la edición de las memorias autobiográficas. Y es que la memoria de Aldo Rossi (basada en las anotaciones escritas desde 1971) "constituye, más que una simple autobiografía o un abstracto texto teórico, un documento de imaginación arquitectónica" (Rossi, 1984: s/p), ya que:

"Su gran interés y su especial encanto está, sobre todo, en el diálogo que el autor establece con su propio pasado y con su trabajo, en la forma en que Rossi deja vagar libremente a sus pensamientos entre recuerdos infantiles [siempre presentes como 'fantasmas del pasado'] y observaciones filosóficas [-y vitales-] acerca de la arquitectura. Repleta de recuerdos y cavilaciones sobre la arquitectura y su enseñanza [ejemplo de la dilatada trayectoria docente], la Autobiografía se revela, al mismo tiempo, como un texto teórico sobre la naturaleza del hecho arquitectónico [y 'hecho urbano'] en nuestros días" (Rossi, 1984: s/p).

Para este autor y colega de A. Rossi, la prosa de éste es también 'como su arquitectura'; "nostálgica, austera, sutil, incisiva y, en todo momento, elegíaca" (Rossi, 1984: s/p). Junto con la narración son fundamentales y decisivos los dibujos, fotografías e ilustraciones -'imágenes evocadoras de memoria' (el poder de la memoria evocadora)-, que el propio Rossi realizó y/o seleccionó para la publicación del texto autobiográfico, ya que es evidente

4 Se ha tomado como texto base la edición en castellano de Gustavo Gili ('Arquitectura ConTextos'), Barcelona, 1984, ya que esta fue, al parecer, la primera traducción al castellano del texto originario de 1981: A Scientific Autobiography, Cambridge \& Massachussets: The Institute for Architecture and Urban Studies// The Massachusetts Institute of Technology, The MIT Press. 
que sus escritos están íntimamente ligados a sus dibujos y proyectos arquitectónicos, representando así el 'flujo' entre pasado y presente.

Con todo, A. Rossi sitúa el punto de partida de su Autobiografía científica (cuya referencia más 'culta' confesada por él mismo es la Autobiografía científica de Max Planck), ese 'implicarse en una mirada retrospectiva que tiene como límite la vida del protagonista' siguiendo la idea de la profesora $\mathrm{M}^{\mathrm{a}}$ Teresa del Valle, diez años antes de la conclusión de los textos, que es cuando comienzan las anotaciones que después darán lugar a la composición de la 'autobiografía...', estructurada desde las primeras hasta las últimas palabras con la narración en primera persona:

"Inicié estas notas hace casi diez años y ahora intento acabarlas para que no se conviertan en memorias" (Rossi, 1984: 9).

En ese preciso momento se introduce un paralelismo que acompaña la búsqueda consciente del hito:

"A partir de un determinado momento de la vida, empecé a considerar el oficio o el arte como descripción de las cosas y de nosotros mismos; por esa razón he admirado siempre la Comedia dantesca, ${ }^{5}$ que comienza a los treinta años del poeta" (Rossi, 1984: 9). ${ }^{6}$

Búsqueda del hito en un determinado período vital -'a los treinta años del autor'-, que es también un punto de intersección y articulación con esa idea de 'poner orden' o 'articular' el discurso sobre este eje en el que se incide:

"A los treinta años hay que concluir o empezar algo definitivo y pasar cuentas con la formación de uno mismo" (Rossi, 1984: 9).

Es además cuando se refiere en términos específicos a sus dibujos y escritos, en lo que se volverá a incidir después:

"Cada uno de mis dibujos o escritos me parecía definitivo por partida doble: porque remataba mi experiencia y porque me dejaba sin nada más que decir" (Rossi, 1984: 9).

'Quedarse sin nada más que decir' es lo que se destaca igualmente en la interrogación retórica que los editores extraen del texto de Rossi para insertarlo al inicio como frase testimonial: “¿a qué podría aspirar en mi oficio? En verdad [sic] a pocas cosas, porque los grandes hechos han prescrito históricamente" . Ese 'silencio', 'vacío conclusivo oteiciano' si se me permite esa terminología, roto únicamente en la autobiografía, que refleja una profunda y un tanto pesimista toma de postura y toma de conciencia con la profesión es lo que se destaca en repetidas ocasiones:

"Estas notas tratan, en realidad, de la disolución de la disciplina, tema no muy diferente del de las observaciones que hacía al inicio de este escrito [...].

5 Existen también otros símiles: “Era la misma postura de los tratadistas respecto a los maestros medievales; [...] admiraba la obstinación de Alberti... >> (Rossi, 1984: 10).

6 Todos los subrayados en negrita que aparecen sobre las citas textuales son a propuesta de la autoría de este texto. Los subrayados en cursiva pertenecen al propio autor (A. Rossi) o a los/as autores/as de las publicaciones citadas. 
Tal disolución es real, aunque no sé hasta qué punto. Tal vez forma parte de esa conciencia de que los grandes hechos ya han prescrito y de que la propia limitación al oficio es una forma de defenderse" (Rossi, 1984: 64).

"Y también he comprendido que estas situaciones generales debían ser vividas personalmente a través de pequeñas cosas, porque los grandes hechos han prescrito históricamente" (Rossi, 1984: 99).

Es de señalar el hecho de que esta idea repetitiva con la que en principio nos encontramos en el encabezamiento del texto, reaparece hacia el ecuador de la 'autobiografía...' (p.64) que tiene escasas cien páginas, y posteriormente casi al final, en la página 99 (ver citas a pie). Sin embargo hay que destacar una clara contradicción a este respecto: "pensando en esas obras me doy cuenta de lo mucho que me interesa lo que está aún sin decir y la forma en cómo podría decirse" , (Rossi, 1984: 16) no es descabellado suponer que no todas las puertas están cerradas, sigue habiendo algún resquicio para el optimismo y la esperanza...

No menos curioso resulta averiguar que esa pértiga temporal que como se ha dicho A. Rossi hace saltar hasta los treinta años, no se retrotrae en absoluto al momento del inicio de las notas transformadas en autobiografía (desde 1971) -puesto que para entonces ya tenía una edad de 40 años-, sino que a lo que se refiere es más concretamente a la hora en la que se empeña en la escritura de La arquitectura de la ciudad, ${ }^{7}$ su contribución teórica más importante que nos ha servido para la introducción de esta trabajo en las anteriores páginas, casi un auténtico tratado urbanístico sobre la ciudad construida y la 'ciudad heredada', que constituye todo un hito en la existencia de A. Rossi puesto que su gran trascendencia en la disciplina arquitectónica y el urbanismo no fue a propósito buscada, aparte de erigirse también en un singular intersticio, un momento 'clarividente' de especial lucidez, precursor de cambios:

"Escrito alrededor de mis treinta años, aquel libro me parecía definitivo y, aún hoy, no han sido sus enunciados ampliados suficientemente. Más tarde advertí con claridad que en la obra latían motivaciones mucho más complejas, especialmente a causa de las analogías que atraviesan todas nuestras acciones [maxime si consideramos, como seguidamente veremos, la importancia de la arquitectura en la vida de Rossi]" (Rossi, 1984: 9).

La arquitectura de la ciudad será, no obstante, uno de los ejes básicos sobre los cuales se estructura la 'autobiografía...', aunque no se haya verbalizado en palabras muy a menudo:

“Alrededor de 1960 escribí [publicado por vez primera entre 1965-66 -véase bibliografía-] La arquitectura de la cuidad, un libro afortunado. No tenía aún treinta años [nace en 1931], pero quería escribir un libro definitivo" (Rossi, 1984: 27).

"Sin embargo, cuando escribí La arquitectura de la ciudad, demostré mi profunda admiración por Viollet-le-Duc [citas y referencias]" (Rossi, 1984: $58)$.

Este ir y venir en el tiempo recorriendo y 'recuperando' mentalmente los 'hitos' más significativos, remite análogamente al tratamiento peculiar que Rossi procura al tiempo, un tiempo vital y matizado que nos ubica en los 'tiempos mecánicos' y ‘tiempos cronológicos'

7 Remítase a la bibliografía adjunta. 
y que en Aldo Rossi adquiere un ‘doble significado': significado “atmosférico y cronológico del tiempo, [...] principio que preside toda construcción” (Rossi, 1984: 9). Afirmaciones que reaparecerán a continuación:

"Fue precisamente visitando San Andrés de Mantua cuando tuve, por vez primera, la sensación de esa correspondencia que existe entre el tiempo en su doble sentido, atmosférico y cronológico, y la arquitectura" (Rossi, 1984: 10).

"Ciertamente, el tiempo del teatro no coincide con el tiempo medido por el reloj [tiempo mecánico]” (Rossi, 1984: 42).

"Así, él me demostró con claridad que luces y sombras no son sino otro aspecto del tiempo cronológico, la fusión del tiempo atmosférico y el cronológico, que muestran la arquitectura y la consumen, otorgándole una breve imagen, tan duradera sin embargo" (Rossi, 1984: 59).

"Las grandes naves que surcaban el río marcaban el tiempo como los botes del lago durante la infancia" (Rossi, 1984: 93).

“Aún pensaba en la máquina de la arquitectura. Pero la máquina de la arquitectura era, en realidad, la máquina del tiempo. [...] Encontré la analogía de la arquitectura en el tiempo y en el lugar. [...] Esta dimensión del tiempo y del espacio podría ser llamada arquitectura, como se llama arquitectura a un monumento" (Rossi, 1984: 95).

"Desde siempre he sabido que la arquitectura está determinada por la hora y la visicitud" (Rossi, 1984: 96).

Unido a ello toda la 'autobiografía...' emana una permanente relación íntima de su vida con su oficio -con la arquitectura- hecho que, como ya se insinuaba más arriba, se hace notar en innumerables comentarios:

“Cada verano veía el último verano, [...] permanencia sin evolución, [...] la clave de muchos de mis proyectos. [...] Para comprender o explicar mi arquitectura, debo caminar a través de cosas e impresiones, describirlas o intentar hacerlo" (Rossi, 1984: 9).

La 'quietud' del 'permanecer sin evolucionar' resuena una y otra vez en sus labios:

"Estoy detenido en una situación, que podría ser toda mi arquitectura, en la que el lugar y el tiempo, aparentemente tan importantes, se disuelven en gestos y recorridos conocidos" (Rossi, 1984: 44).

"Esa imposibilidad de evolucionar es el origen de algunas de mis desventuras, pero la siento también, con alegría [-¿felicidad?-], como algo que me pertenece" (Rossi, 1984: 51).

La 'muerte' y la 'felicidad' persisten extrañamente en Rossi, como se observa en estas citas que vuelven a aludir a autores mencionados: 
"Quizás parezca extraño que tanto Planck como Dante asocien su búsqueda científica y autobiográfica con la muerte; una muerte, sin embargo, que es en cierta forma continuación de energía (Rossi, 1984: 37). De hecho, en todo artista o técnico, el principio de continuidad de la energía se confunde con la búsqueda de la felicidad y de la muerte [pilares básicos para A. Rossi en relación con su trayectoria VITAL, tal y como se derivará de algunos proyectos que comentaremos después, sea el caso del cementerio de Modena]. Esa búsqueda también está ligada, en arquitectura, al material y a la energía, y, sin advertir tal cosa, no puede comprenderse construcción alguna, ni en sus aspectos técnicos, ni en los compositivos. Al utilizar cada material debe atenderse a la construcción del lugar y a su transformación [en ello subyace el compromiso con el OFICIO]" (Rossi, 1984: 9).

La arquitectura es en todo caso 'una cuestión vital', además del modo 'existencial' de habitar en el espacio: ${ }^{8}$

"La arquitectura era uno de los modos de supervivencia que habían perseguido los hombres, una manera de expresar su esencial búsqueda de la felicidad" (Rossi, 1984: 10).

La relación vida-arquitectura se intensifica en los siguientes extractos:

"Precisamente porque estoy escribiendo una autobiografía de mis proyectos que se confunde con mi propia historia..." ((Rossi, 1984: 16).

“Desestimaba los recuerdos [¿acaso búsqueda 'consciente' del olvido?] y, al mismo tiempo, me servía de mis impresiones urbanas; buscaba, tras los sentimientos, leyes inmóviles de una tipología [arquitectónica] situada fuera del tiempo. [...] Descubría mi arquitectura. [...] Lo buscaba en la historia, lo traducía en mi historia [en una búsqueda que se dirige de lo genérico a la particularidad del universo personal]. Todo esto me ha conducido a la idea de identidad" (Rossi, 1984: 27).

"El proyecto se convertía en el simple pretexto de una conmoción más general: muchas de las limitaciones de mi obra tan solo se explican a través de esta sencilla y conquistada capacidad de ver" (Rossi, 1984: 31).

"Siempre he afirmado que los lugares son más fuertes que las personas, el escenario más que el acontecimiento [la 'escenografía' para el 'teatro']. Esta es la base teórica no solo de mi arquitectura, sino de la arquitectura en general; en esencia, una posibilidad de vida. [...] En mis proyectos siempre he pensado en estas cosas..." (Rossi, 1984: 75-76).

\footnotetext{
8 Por medio de la construcción logramos habitar; lo cual significa que poseemos una morada. Ese permanecer en un lugar determinado constituye el acto de habitar, en definitiva, el término ordinario de ese 'construir'. Así pues, construir sería levantar por medio de esos elementos y componentes; del mismo modo que habitar, es en esencia cuidar y proteger dicha construcción. Esos lugares que construimos, son después habitados; de igual manera que ese lugar o sitio forma una región, relacionando las cosas entre sí en su interior. En este sentido, el espacio constituiría la adaptación de los lugares de una región. Si los elementos de una construcción cumplen su función, se convierten en parte de una realidad espacial, ya que edificar es en esencia 'hacer habitar'. De modo que el fin último de la edificación será construir lugares a partir de la unión de sus espacios.
} 
"Hoy veo mis viajes familiares y privados como públicos o científicos, porque en ellos descubro el pasado y el presente, y el valor que hay en cada afirmación y en cada mirada distraída ['mirada distraída' que no es tal, pues ese 'estar alerta' es continuo en todas sus actitudes]" (Rossi, 1984: 64).

"Debería hablar ahora de mis obras construidas, que tal vez sean pocas, pero que, si las identifico con una parte de mí mismo, constituyen el punto central de su biografía, o autobiografía” (Rossi, 1984: 71).

"Me gusta comprender las grandes líneas de la estructura y pensar, después, en cómo estas líneas se pueden cruzar. No es demasiado distinto de la vida y las relaciones..." (Rossi, 1984: 75-76).

Es quizás en este punto donde hallamos la clave de gran parte de las cuestiones, cuando Rossi enlaza ARQUITECTURA con MEMORIA, sobre lo cual más adelante también se incidirá:

"Durante algunos años todo esto pareció responder a mis preguntas, a mi interés por las cosas, y, también, por la arquitectura. La memoria se construía con su propia especificidad, y tal construcción, se defendiera o no de las estructuras extrañas, tenía el poder de reconocerlas. Ahí se encontraba la relación del hombre con la ciudad, con la construcción de su microclima, con su especificidad" (Rossi, 1984: 77).

"Creo que, ahora, estos proyectos y construcciones pueden entenderse en relación con las estaciones y las edades de la vida; entre la casa de la infancia y de la muerte, está el teatro o la casa de la representación [se instaura el MONUMENTO]. Y no estoy hablando de temas y, aún menos, de funciones, sino de las formas en que la vida, y, por tanto, la muerte, se manifiesta" (Rossi, 1984: 86).

Se correlaciona igualmente ARQUITECTURA con ANTROPOLOGÍA, respondiendo eficazmente a una mirada antropológica de la arquitectura:

"Pero al hablar de la vida del hombre [individuo -anthropos-] debo aclarar, ante todo, aquellos aspectos de la vida de la sociedad [cultura y sociedad -etnos-] que desde la juventud han impresionado con mayor fuerza mi mirada arqueológica y antropológica. Anteriormente me he referido ya a los corrales de Sevilla, a los patios de Milán, incluso al patio del Hotel Sirena. Y a los corredores, a las galerías, a los pasillos, a la impresión literaria y real de los conventos, de las escuelas, de los cuarteles. Finalmente, tales formas de vivienda -junto con la villa- se han ido depositando en la historia del hombre para acabar perteneciendo tanto a la arquitectura como a la antropología" (Rossi, 1984: 86).

Esta toma de partido es inseparable de la idea de toda una vida afiliada al oficio de arquitecto que correlativamente se pone de manifiesto en los párrafos que se están entresacando y valorando, con el transcurso entre el tiempo pretérito, el presente y el más o menos probable futuro incierto: 
"Todo esto permite la representación del pasado con el deseo del presente [retomar el pasado]; lo que más me asusta es el pasado de un hombre para quien el deseo del presente haya muerto: por eso, paradójicamente, el pasado tiene los colores del porvenir y de la esperanza. Ninguno de mis proyectos se aleja del pasado, quizás porque nunca he expresado toda la alegría de futuro que un proyecto, un objeto, una persona, un viaje, tienen para mí. No sé hasta qué punto pueda esto significar alegría [¿felicidad?] o melancolía [¿expiración?], pero creo que es una condición para vivir y trabajar en el propio oficio". Es en este punto donde introduce su única alusión a la experiencia cinematográfica: "mi única experiencia en el campo del cine la tuve en la Trienal de Milán de 1973; pusimos al film el título del hermoso ensayo de Adolf Loos Ornamento $y$ delito. Era un collage de obras arquitectónicas y fragmentos de films, en un intento de introducir el discurso de la arquitectura en la vida" (Rossi, 1984: $88)$.

"Tan solo algunos arquitectos modernos me gustaban, pero de esos me considero discípulo: por encima de todo, Adolf Loos y Mies van der Rohe. Ellos son quienes más claramente han establecido un hilo de continuidad entre su historia y la historia del hombre [ARQUITECTURA-ANTROPOLOGÍA]" (Rossi, 1984: 89). ${ }^{9}$

"Por eso, aún a costa de repetir cosas ya escritas, describo así mis proyectos: porque no creo que existan diferencias entre el apunte personal y la descripción, entre la autobiografía y la técnica, entre lo que podría ser y lo que no es" (Rossi, 1984: 94).

La arquitectura es siempre un reflejo y se realiza desde las experiencias más íntimas:

"Así, pues, toda arquitectura es, ciertamente una arquitectura del interior, o, mejor aún, desde el interior” (Rossi, 1984: 37).

"Los puestos de venta del interior de los mercados o los confesionarios y las capillas de las catedrales, nos explican esta relación entre lo particular y lo universal, restituyendo la relación entre interior y exterior de la arquitectura" (Rossi, 1984: 38).

Para completar esta 'secuencia', en el último párrafo de la 'autobiografía...' A. Rossi dedica otra referencia importante que relaciona vida con arquitectura, clausurando así el texto autobiográfico:

\footnotetext{
9 Decir una vez más que es palpable la opinión ciertamente negativa que A. Rossi manifiesta acerca de los 'racionalismos' de la arquitectura moderna, desplazándose notablemente de esas tendencias, ya que " de este modo creía ir más lejos que cualquier superficial vanguardia [Rossi, 1984: 88] >>. Dichas desavenencias pueden observarse igualmente en su postura escéptica sobre los postulados de Le Corbusier y la Carta de Atenas de 1933, que propiciaba el camino hacia los conceptos a la larga mal comprendidos y especulativos de "ciudad abierta' y 'ciudad difusa': " dedo decir que, a pesar mío, he mantenido siempre una postura ambigua respecto a la arquitectura moderna [Rossi, 1984: 89] >>, al igual que el rotundo rechazo de la arquitectura tecnócrata que se gestará tiempo después a raíz del tan manido 'estilo internacional' en arquitectura: “el estimar unas técnicas como superiores o más apropiadas que otras es una de las muestras de locura de la arquitectura contemporánea y de la mentalidad iluminista de la cultura de los Politécnicos, que se transmitió sin variaciones al Movimiento Moderno >> (Rossi, 1984: 89).
} 
"Había pensado analizar, en este libro, mis proyectos y escritos, mi trabajo, como en una secuencia continua: comprendiéndolos, explicándolos, y volviéndolos a proyectar al mismo tiempo. Pero ahora veo que el resultado ha sido otro proyecto, que contiene, también, algo de imprevisible y de improvisto. [...] Otros recuerdos, otros motivos, han ido apareciendo, también aquí en discreto desorden, y así se ha ido modificando el proyecto original, que yo estimaba mucho. [...] Tal vez, la historia de un proyecto deba ser simplemente así, y, al igual que el proyecto, necesite de una conclusión, quizá tan sólo para poder ser repetida con pequeñas variaciones y movimientos, o, también, para no resultar asimilada a nuevos proyectos, nuevos lugares y nuevas técnicas, otras formas de vida que siempre entrevemos" (Rossi, 1984: 100).

Aparecen así mismo paradojas de posibles ‘vidas paralelas imaginadas' acerca de lo que se vierten justificaciones intelectuales:

“...seguramente repetiría igual cada proyecto. Pero lo cierto es que todo lo pasado se convierte en historia, y se hace difícil pensar que las cosas pudieran haber ocurrido de otro modo" (Rossi, 1984: 24).

"Así, pues, toda arquitectura es, ciertamente una arquitectura del interior, o, mejor aún, desde el interior” (Rossi, 1984: 24).

"Los puestos de venta del interior de los mercados o los confesionarios y las capillas de las catedrales, nos explican esta relación entre lo particular y lo universal, restituyendo la relación entre interior y exterior de la arquitectura" (Rossi, 1984: 37).

"Había pensado analizar, en este libro, mis proyectos y escritos, mi trabajo, como en una secuencia continua: comprendiéndolos, explicándolos, y volviéndolos a proyectar al mismo tiempo. Pero ahora veo que el resultado ha sido otro proyecto, que contiene, también, algo de imprevisible y de improvisto. [...] Otros recuerdos, otros motivos, han ido apareciendo, también aquí en discreto desorden, y así se ha ido modificando el proyecto original, que yo estimaba mucho. [...] Tal vez, la historia de un proyecto deba ser simplemente así, y, al igual que el proyecto, necesite de una conclusión, quizá tan sólo para poder ser repetida con pequeñas variaciones y movimientos, o, también, para no resultar asimilada a nuevos proyectos, nuevos lugares y nuevas técnicas, otras formas de vida que siempre entrevemos" (Rossi, 1984: 100).

“...seguramente repetiría igual cada proyecto. Pero lo cierto es que todo lo pasado se convierte en historia, y se hace difícil pensar que las cosas pudieran haber ocurrido de otro modo" (Rossi, 1984: 24).

"Habría podido llevar por título Olvidar la arquitectura [referencia a un escrito], porque puedo hablar de una escuela, de un cementerio, de un teatro, pero siempre será más exacto decir: la vida, la muerte, la imaginación" (Rossi, 1984: 94).

"Estas circunstancias estaban en la base de un proyecto que he descrito varias veces en formas diversas, y que titulé Proyecto de villa con interior [proyecto 'fantasma' que ronda en su memoria]. También habría podido llamarlo Olvidar 
la arquitectura [referencia a una obra proyectada, trazada, 'dibujada' o quizás 'desdibujada']. Hace tiempo que creo haber renunciado a ese proyecto, aunque hable de él a menudo y aparece en muchos de mis papeles, en dibujos inacabados o esquemas, en postales y fotografías..." (Rossi, 1984: 44).

Antes decía que el libro La arquitectura de la ciudad había constituido de los ejes básicos estructurantes sobre los cuales se organiza la 'autobiografía...'. Aunque no existen capítulos ni apartados, por lo que se ofrece al lector un texto continuo sin 'parcelaciones', hay sin embargo una estructura implícita en partes subyacentes que va articulando la narración autobiográfica. Estas 'fases' no explicitadas coinciden en nuestra opinión con 'hitos' importantes que han marcado para la posteridad la trayectoria tanto profesional como personal, inseparablemente lo uno de lo otro, del arquitecto Aldo Rossi. Estos apartados ocultos sintonizan con regresiones temporales, cambios cronológicos y con el tono de cada recuerdo en los períodos de vida -y obra- que se recopilan.

Otro de estos ejes internos al cual se aferra frecuentemente son algunos de sus proyectos arquitectónicos más emblemáticos, que asoman tal que 'hitos' característicos de la vida científica y personal -etapas de la vida y de su arquitectura- que articulan un pensamiento:

"Continuaré estas notas autobiográficas hablando de algunos proyectos que han caracterizado determinados momentos de mi vida; son muy conocidos, y siempre he evitado un comentario directo sobre ellos. En primer lugar, [...] el cementerio de Módena [Fig.2], y, después, el de la residencia de de Chieti [ambos están bien presentes en Rossi]. El primero, por su mismo tema, expresa el fin de mi adolescencia y de mi interés por la muerte; ${ }^{10}$ el otro, una búsqueda de felicidad como condición de madurez [sentimientos muy arraigados como se ha visto]. El primer proyecto está ligado a circunstancias concretas y al fin de mi investigación sobre una idea osteológica del fragmento; el segundo, a una situación de felicidad" (Rossi, 1984: 20).

"Esas secciones inacabadas eran, de nuevo, las de la "fábrica" de la residencia de estudiantes de Chieti” (Rossi, 1984: 75).

La identificación como hitos se descubrirá, no obstante, más tarde:

"Sin embargo, comprendí gran parte del significado de estos proyectos en 1975, cuando, entre ambos [intermedio], realicé el del Palazzo della Regione de Trieste" (Rossi, 1984: 20).

Particularmente el proyecto para el cementerio de Módena, constituye a la vez un hito significativo e instante de clarividencia ${ }^{11}$ a raíz de una convalecencia hospitalaria (por lo tanto se asimilará como un hecho negativo en cuanto a lo que se denomina como 'vida', pero muy positivo a su vez desde la vertiente enriquecedora de su obra). Vuelve a haber una regresión a un tiempo pasado en el que las fechas se citan directa o indirectamente, además de constituir el momento de inicio de las notas que después serán fruto de la 'autobiografía...', en $1971 .{ }^{12}$ La experiencia del dolor físico corporal (-dolor de huesos-) que evoca re-

10 “ Pretendía acabar con un problema de juventud: el de la muerte como representación>> (Rossi, 1984: 49). 11 'Intersticios' que en todo caso serían asonantes, pues no mantienen necesariamente una armonía.

12 Se explicita el 'retorno del hito a la memoria': "Todavía quiero decir algunas cosas sobre el cementerio de Módena, cuya primera redacción, motivada por un concurso, es de 1971. Del mismo año, aproximadamente, son las primeras notas de este escrito... >> (Rossi, 1984: 49). 
cuerdos de otras épocas de la vida, podría quizás asociarse en este sentido a cierta 'memoria del cuerpo'. Aunque la acción se presenta como concluida, sin intermedio, sin explicar el proyecto -'evitando comentarios sobre ellos'- en una especie de 'olvido consciente' como se decía anteriormente-, que luego regresa, en cambio, a los prolegómenos:

"A mediados de 1971, en abril, sufrí un grave accidente de tráfico en la carretera de Estambul, entre Belgrado y Zagravia. Tal vez a consecuencia suya, como he dicho, nació en el pequeño hospital de Slawonski Brod, al mismo tiempo que concluía mi juventud, el proyecto del cementerio de Módena. [...] Al mismo tiempo, esa lejanía de las cosas -unida, además, a la dolorosa conciencia de mis propios huesos- me transportaba a la infancia..." (Rossi, 1984: 22).

"Siempre tuve presente este hospicio durante la redacción del proyecto de Módena, y la luz que penetra por sus vidrieras es la misma que en aquel atraviesa, con precisos rayos, la sección del cubo [paralelismo, -'la luz tenue en el resquicio del camarote...'-]" (Rossi, 1984: 23).

"Su ritmo de construcción es el de la mortandad urbana y, por tanto, hay en ella un tiempo ligado a la vida, al igual que, por otra parte, ocurre con todas las construcciones" (Rossi, 1984: 24). ${ }^{13}$

“...gran proyecto sobre la casa de la muerte, que es el del cementerio de Módena” (Rossi, 1984: 71).

En estos 'apartados' referentes a los proyectos arquitectónicos hay un subgrupo dedicado a los teatros, que despiertan un considerable interés a Rossi desde el punto de vista de la 'comedia' que se veía al principio, en relación con las 'edades de la vida' y la memoria:

"Sea como sea, al pensar en los mercados establezco siempre un paralelo con el teatro y, de forma especial, con el teatro del siglo XVIII, por la relación que existe entre los palcos como lugares aislados y su espacio general. En toda mi arquitectura se refleja mi pasión por el teatro, aunque, de hecho, tan solo he proyectado tres: el Teatro Paganini, en la plaza de la Pilotta de Parma como obra de juventud; el proyecto para el Teatrino Scientifico en 1979, y, más recientemente, el Teatro del Mondo de Venecia" (Rossi, 1984: 38, 40).

"Las casas - barracón de la residencia de estudiantes de Chieti y de los dibujos de las casetas de la playa de Elba, [...] eran los pedazos de un sistema que debía recomponerse en el interior del Teatrino Scientifico. [...] Tales primeros compases son siempre un inicio [vuelta a los orígenes], y tienen toda su magia.

13 El cementerio como 'lugar para la memoria de los vivos': “ La idea central del proyecto surgía, tal vez, de haber advertido que las cosas, los objetos, las construcciones de los muertos, no son diferentes a las de los vivos $>>$ (Rossi, 1984: 50). Esto conduce así mismo a las siguientes consideraciones, esto es, que 'el cementerio y ciudad son inseparables'. "De tal manera, que para referirnos a él [-cementerio-] usamos las mismas palabras que para referirnos al concepto de habitar en vida. El lenguaje tópico y común lo designa como un lugar para la muerte [presencia de la muerte en Rossi]: la ciudad de los muertos. El cementerio, identificado desde sus comienzos [...] con la ciudad de los vivos, funciona como su doble desde el mismo momento que empieza a configurarse en la imaginación del arquitecto. La ciudad de los vivos adquiere significación con el tiempo. Es el tiempo, el pasado visto desde el presente [semejante al tiempo biográfico/ autobiográfico], el que ha depositado objetos en el espacio. Edificios, plazas, jardines, monumentos, instalados según los acontecimientos de la historia, dan forma a los lugares que significan la ciudad” (Arnaiz, 1995: 284). 
Al mirar los teatros vacíos como construcciones abandonadas para siempre me doy cuenta de todo esto, aunque ese abandono es a menudo más breve que la luz del día; pero está tan cargado de memoria que construye el teatro" (Rossi, 1984: 42).

"Pensaba yo en dos comedias que podrían alternarse continuamente: una se titula Los irreconciliables, la otra, Los reunidos [aparente contradicción]. Personas, experiencias, cosas, fragmentos, arquitectura, tienen siempre un precedente o una continuación que se superponen recíprocamente" (Rossi, 1984: 43).

"Pero quiero hablar ahora de Venecia porque para ella he realizado mi último proyecto: el teatro flotante de la Biennal de 19179-80" (Rossi, 1984: 79).

"De eso trataba la primera idea del Teatro Scientifico, ligada como estaba a la comedia Die nicht Versöhnt, los irreconciliables, ya que era la historia de aquellos que, tras algún acontecimiento, no podían reconciliarse, pero, ante todo, porque estaba dedicada a quienes no podían hacerlo porque el acontecimiento ni siquiera se había producido. Los irreconciliables no son, necesariamente, la otra cara de los reunidos, aunque me gustaba ver mezcladas ambas comedias" (Rossi, 1984: 81).

Idea filosófica en la que se 'apoya' su hacer profesional y los 'hechos arquitectónicos':

"La irreconciliación pueda convertirse en una forma de ser. Y en esta idea se apoyaba y crecía mi arquitectura, en la que las analogías no se suceden como figuras de la baraja -la sota, el caballo, el rey, el as- sino que reconstruyen un mundo en el que las cosas se contraponen" (Rossi, 1984: 81).

En relación con estos proyectos se produce otro punto de inflexión, apelando a un 'recuerdo - memoria' unido a la arquitectura que se debate entre 'atrapar esa memoria' o en su defecto permitir un circuito de flujo imparable: ${ }^{14}$

"Aquí podría detenerse la relación de los proyectos, o, si se quiere, iniciarse una desmesurada búsqueda de las cosas. Búsqueda que es recuerdo, pero, sobre todo, la vertiente exterminadora de la experiencia, que actúa sin avisar, concediendo o quitando significados a cada proyecto, suceso, persona o cosa" (Rossi, 1984: 47). ${ }^{15}$

"Tal vez el signo puede sufrir cambios en las narraciones, pero solo aquellos signos tangibles, por medio de los que nos comunicamos, forman lo que aún podemos llamar historia o proyecto. Más allá de la identificación con la cosa,

14 Ya que es cierto que no solamente 'mantenemos la memoria del pasado', sino también la 'memoria del futuro' como advierte José Antonio Marina. Como somos ‘organismos autopoéticos' capacitados para 'construirnos' y modelarnos en el transcurso de 'nuestra historia', "la memoria en ocasiones se convierte en ficción, pero también se da el caso de que la imaginación recuerde..." (Muñoz Molina, 65).

15 “ Si tuviera que hablar de la arquitectura, diría que es más bien un rito que un acto creativo; porque conozco perfectamente las amarguras y el consuelo del rito. El rito nos consuela con la continuidad, con la repetición, nos obliga a oblicuos olvidos, porque, no pudiéndose desarrollar, cualquier cambio significaría su destrucción>> (Rossi, 1984: 48). 
ésta es la constatación o el descubrimiento de Loos ante el túmulo. ${ }^{16}[\ldots]$ Se trata, en el fondo, del túmulo o del palacio, o de todo aquello capaz de anticipar sucesos que, en realidad, ya se han dado en otro lugar, en cualquier parte, también aquí. [...] Para alcanzar su grandeza, la arquitectura debe ser olvidada o constituir tan sólo una imagen de referencia confundida con los recuerdos. [MEMORIA $\square$ RECUERDO] La arquitectura debe tener pocas características, sólo aquellas que sirvan a la fantasía o a la fascinación: incluso los escuálidos funcionalistas habían comprendido algo de esto" (Rossi, 1984: 57).

"Podría hablar de mis relaciones con las ciudades igual que lo hago de mis relaciones con la gente, aunque, de alguna manera, las primeras son más ricas porque comprenden a las segundas. Eso es especialmente cierto cuando en alguna ciudad se produce un acontecimiento [que suscita 'memorias' y 'recuerdos']. Esas relaciones permanecen fijas en el recuerdo que queda superado el símbolo, como podía ocurrir, [...] con las amarillentas fotografías [...]. Siempre he encontrado esos puntos de unión entre historia personal y civil llenos de significado [IMAGEN/ MEMORIA $\mathrm{RECUERDO]"} \mathrm{(Rossi,} \mathrm{1984:}$ 77). ${ }^{17}$

Dentro de esas 'partes que se articulan' surge también con especial vividez una ‘vuelta a la juventud' con la polémica y controversia que suscitó en su tiempo la defensa por parte de Rossi de la arquitectura del realismo socialista, tras una histórica visita como invitado a la Unión Soviética, por lo que a posteriori se entresacan unas certeras conclusiones acerca de los 'lugares' -'locus'- y las 'identidades':

"Hablando de estos lugares, de la Rusia de mi juventud, de los demás, puedo ver de qué forma una investigación científica sobre la propia obra se convierte en una especie de geografía de la educación. Y quizás, desarrollando este texto en otro sentido, habría podido titularlo Geografía de mis proyectos [otra vez la paradoja en el título de un texto escrito]. Todo lugar es único justamente en la medida en que se dan en él determinadas afinidades o analogías con otros lugares; como he dicho, incluso el concepto de identidad, y, por tanto, el de diferencia, es relativo. Cada lugar es recordado en la medida en que se convierte en lugar de afectos o en la medida en que llegamos a identificarnos con él" (Rossi, 1984: 52).

Por último, nos disponemos a señalar aquí la importancia que Rossi otorga al hecho dibujístico intercaladamente en la 'autobiografía...', como parte esencial y fundamental de la arquitectura, reflexionando acerca de su validez como experiencia personal y como esbozo de arquitectura:

16 Explicando someramente el 'mito' del túmulo de Adolf Loos, éste decía que cuando caminamos por el bosque y nos topamos ante nosotros con un túmulo, hecho con tierra, de 'varios pies de ancho y de alto'; nos ponemos muy serios e inmediatamente replicamos: ahí hay alguien enterrado. Eso mismo sería una sensación primaria de arquitectura en su estado más bruto, pero también en el sentido más amplio.

17 "La fuerza de la realidad que poseen los documentos visuales (fotografías, películas) explica que bastantes autobiografías lleven en la portada una foto del autor cuando era niño, como es el caso de la edición de bolsillo...”. Terenci Moix, El cine de los sábados, Plaza y Janés, Barcelona 1993, s/p. (citado por Fernández Prieto, 1997: 73). "Se recurre incluso al intercambio de recuerdos, al cotejado de diferentes versiones (familiares, amigos) sobre los mismos sucesos, a la revisión de documentos, cartas, agendas, diarios, notas, facturas, etc., y a las fotografías". Ibíd. 
"En mis dibujos L'architecture assassinée y Le cabine dell'Elba entre otros, he querido expresar ese tipo de relaciones" (Rossi, 1984: 27).

Algunos de estos bocetos frecuentemente repetidos aparecen en ocasiones asociados a imágenes de recuerdos 'fugaces', tal que 'sombras chinescas' que se 'dibujan en la memoria':

"En el proyecto de Chieti y en el dibujo, tan reproducido que podría calificar de famoso, Le cabine dell 'Elba ${ }^{18}$, tomé conciencia de estas cuestiones" (Rossi, 1984: 37).

"Primeros dibujos de Le cabine dell'Elba, que son, más o menos, de 1973. [...] En 1976 asocié mi proyecto de residencia de estudiantes de Chieti a esta idea [Fig. 1]" (Rossi, 1984: 53).

"La dificultad de la palabra da lugar, a menudo, a una inagotable fluidez verbal, como el caso de Hamlet o Mercurio. [...] es una manera de hablar de todo y de nada, algo parecido a la grafomanía. Me encuentro con esto en muchos dibujos, sobre todo en los que la línea deja de serlo para convertirse en escritura [obsérvese el trazo de Rossi, figs. 1-2]. Estuve, durante tiempo, a la vez fascinado e inquieto por esa grafía que se sitúa en un punto intermedio entre dibujo y escritura [de ahí la importancia en la 'autobiografía...' también de los trazados gráficos sobre todo a mano alzada]. Es algo así como dibujos escritos: por ella admiraba a Giacometti y a los manieristas del siglo XVI. Lo mismo me ocurría con las afirmaciones de Adolf Loos, porque ni su carácter bíblico ni su pertenencia a una especie de lógica ahistórica de la arquitectura, admitían ulteriores desarrollos" (Rossi, 1984: 56).

Rossi habla, finalmente, de las posibles claves interpretativas -más bien de su negaciónreferidas a esos dibujos esquemáticos equidistantes entre el afán artístico personal -lo que él denomina 'grafomanía' (límite fronterizo entre ESCRITURA y DIBUJO)- y el tecnicismo científico profesional:

"No quiero interpretar esos dibujos, para no caer en una postura mecánica, aunque es indudable que en ellos el elemento personal, casi privado, se mezcla con la búsqueda de la arquitectura [idea clave que regirá toda su vida y obra, como se ha venido señalando repetidamente hasta ahora]" (Rossi, 1984: 75).

\section{II.1. Aldo Rossi. Identidad, memoria e itinerario científico de un arquitecto}

"Esta dimensión del tiempo y del espacio podría ser llamada arquitectura, como se llama arquitectura a un monumento" (Aldo Rossi).

Si hasta el momento han protagonizado este análisis los 'recuerdos' y las 'memorias' -la memoria histórica bajo unos 'procesos de selección de recuerdos'-, no sería lícito 'olvidar'

18 Acerca de las 'casetas que se alinean sobre la arena' se dice: “ en cualquier fragmento manierista, en el templo de Alberti, en las fábricas y en los mercados de fin de siglo, en los templetes adosados a las iglesias y, sobre todo, en los confesionarios, se da la traducción arquitectónica de todas esas cosas. Los confesionarios son casitas colocadas dentro de la arquitectura, y muestran cómo la catedral de la ciudad antigua era una parte cubierta de la propia ciudad >> (Rossi, 1984: 38). 
generando una redundancia que existen igualmente 'olvidos' más o menos manifiestos, esas ‘censuras íntimas' que indican cómo "la literatura también está hecha de olvido. El recuerdo voluntario o consciente es sólo una de las manifestaciones o las tareas de la memoria. [...] Otro oficio de la memoria es la edificación del pasado, en cuyos materiales constructivos suelen mezclarse la verdad y la mentira [con claras alusiones al 'hecho urbano y arquitectónico' ${ }^{19}$ y al 'oficio' tan presente en Rossi]". ${ }^{20}$ Categoría que A. Rossi trata conscientemente demostrando que "aquí el olvido tiene, para mí, un significado casi progresivo; es el caso de quien ha llegado tan lejos en una exploración que ha olvidado ya los motivos que le empujaron a emprenderla, o el de quien utiliza un instrumento capaz de revelarle algo más sobre el mundo sin conseguir que lo haga; en ambos casos queda, tras el intento, el placer de la fatiga” (Rossi, 1984: 61). El ‘olvido’ adquiere además en Rossi un sentido de ‘distracción’:

"A menudo olvido las voces y sitúo personas diferentes en los mismos escenarios, en los mismos lugares, y no lo hago inconscientemente, porque creo que es necesario distraerse de muchas cosas" (Rossi, 1984: 87).

Evidencias que tienen sus consecuencias en la vida profesional y en la obra proyectada y/o construida:

“Creo que el proyecto tanto puede ser una conclusión, como quedar realmente olvidado y resultar traspasado a otras personas o situaciones. Este olvido es también una pérdida de nuestra identidad y de las cosas que observamos..." (Rossi, 1984: 52).

Siguiendo con los olvidos conscientes o inconscientes, en el texto autobiográfico hay períodos y etapas de la vida que quedan relegadas a ese 'no-recuerdo' unas veces buscado y otras sobre-venido. Tal es así que algunas vicisitudes 'no confesadas del todo' que no se 'recuerdan' delatan por ejemplo las escasas referencias a la formación y a su carrera docente, tan dilatada por otro lado. Todo ello aparece con una claridad meridiana en las reflexiones de Rossi repletas de 'vacíos':

"Mi primera educación no fue exactamente figurativa, [...] habría podido dedicarme a cualquier cosa y [-aparente contradicción paradójica-], de hecho, mi interés por la arquitectura y mi actividad como arquitecto se inician con bastante retraso" (Rossi, 1984: 10).

"Esa búsqueda me conmueve aún [-regreso-] en los hallazgos arqueológicos, en el barro cocido, en los utensilios, en los fragmentos donde la piedra antigua se confunde con un hueso en el que, a su vez, se diluye la forma del esqueleto. Por eso gusto de los museos de paleontología y de pacientes reconstrucciones de pedazos que no pretenden dar sentido a una forma definitiva. Ese cariño por el fragmento y por el objeto se dirige a cosas aparentemente insignificantes a las que otorgamos la misma importancia que se da, por lo común, al arte" (Rossi, 1984: 10).

Se refiere en algunos momentos a imágenes que le han impactado en su infancia: 'hitos'

19 Puesto que como acto colectivo en el que se inmiscuye la memoria, "forma parte de la vida social, de la historia de los grupos y de la identidad comunitaria”. (Blanco, 1997: 90).

20 "Ya dijo William James que a lo que principalmente se dedica la memoria es a olvidar". (Muñoz Molina, 1997: 57). 
personales erigidos en monumentos arquitectónicos (imágenes evocadoras de la arquitectura religiosa):

"Finalmente, al referirme a mi educación infantil, no puedo olvidar [los] Sacri Monti $^{21}[\ldots]$ mi primer contacto con el arte figurativo" (Rossi, 1984: 15).

Es igualmente parco cuando se trata de las apreciaciones sobre su carrera como enseñante:

"Resulta ahora curiosos, pues, que iniciase mi carrera académica como profesor agregado de "caracteres distributivos de los edificios", una asignatura hoy desaparecida, y que viera en esa trama de recorridos y dimensiones el alma o el esqueleto de la arquitectura" (Rossi, 1984: 16).

Hay también aspectos estrechamente relacionados con su formación en los que se confirma su condición de 'arquitecto teórico', donde tampoco falta cierta ironía:

"Mientras dirigía las pocas obras que he construido, gustaba de los errores que en ellas se producían, de las pequeñas desviaciones, de los cambios para los que debe hallarse una solución inesperada. Me parecía como si el edificio ya estuviera vivo, y eso me causaba admiración: creo que un orden es auténtico sólo si puede admitir cualquier cambio práctico y todos los errores de la debilidad humana. Por eso he dirigido siempre mi interés hacia un orden que es diferente del de mis contemporáneos y profesores [compromiso, -toma de partido con el oficio-], ${ }^{22}$ y también por eso, creo haber sido uno de los peores alumnos del Politécnico de Milán, aunque las críticas que entonces se me hacían son hoy, para mí, las mayores alabanzas que jamás haya recibido. El profesor Sabbioni, por quien sentía un especial afecto, quería disuadirme de mis estudios de arquitectura diciéndome que mis dibujos eran como los de los albañiles o de los maestros de obras que lanzaban una piedra para indicar el lugar en el que debía de abrirse una ventana. Esta observación, que provocaba la hilaridad de mis compañeros, me llenaba de alegría; y hoy intento recuperar aquella felicidad del dibujo confundido con la impericia y la estupidez, y que después ha caracterizado mi obra" (Rossi, 1984: 50). ello:

Existe, sin embargo, un conocimiento expreso de esa carencia y una conciencia sobre

"Una autobiografía científica debería seguramente prestar más atención a mi formación arquitectónica antigua y reciente, pero creo que estas notas, [...] explican bien cómo ha sido, tanto en la teoría como en la práctica. Esta

21 Siguiendo a Anna Tomlinson, el 'monte sacro' se refería a una expresión característica de la religiosidad lombarda durante el manierismo (sucesión de capillas que, representando diversos momentos de alguna historia sacra, deben ser visitadas por los peregrinos con un recorrido que respete el orden de esa historia, cuya culminación, al final del recorrido procesional, reproduce el santo Sepulcro.

22 Ese 'no encontrar lugar' se produce además de modo explícito e irrevocable: “ me resulta difícil situarme entre mis contemporáneos $>>$ (Rossi, 1984: 66). Esa misma sensación sucede en ocasiones con los 'lugares' en su sentido físico y espacial, pero también metafórico y alegórico: "siempre procuro eludir el hablar de Venecia, aunque es el lugar en el que enseño y en el que, irregularmente, vivo desde hace quince años. Es curioso cómo en ella, donde han ocurrido tantas cosas importantes para mí, soy relativamente un extraño -ciertamente en mayor medida que en Trieste o en Nueva York, o en tantas otras ciudades >> (Rossi, 1984: 79). 
formación se identifica con frecuencia en el objeto y en la geografía, en un objeto doméstico o en una fotografía del Partenón o de la mezquita de Bursa" (Rossi, 1984: 64).

En un determinado instante se da constancia de una etapa formativa insólita:

"Este mismo interés me impulsó, en mi primera juventud, a estudiar química y biología, porque siempre he creído que la mente y el cuerpo del hombre están muy ligados a su fantasía. Aún hoy me interesa más cualquier libro de medicina que otro de psicología, sobre todo si es de esa psicología literaria que ha estado de moda en los últimos años. Incluso las explicaciones de enfermedades a partir de motivos psicológicos me han parecido siempre equivocadas; la enfermedad depende de una serie de defensas y resistencias del material que, bien están ligadas a la naturaleza, bien a su historia, bien a la mecánica de su historia" (Rossi, 1984: 76).

Tal y como se decía en el prólogo introductorio, A. Rossi se interesa por los fenómenos y estrategias urbanísticas y planificadoras que inciden en la ciudad americana -aunque en ningún momento cita en este contexto, por ejemplo al arquitecto Kevin Lynch (ya sea por negación, incomprensión o 'simple olvido')-, imposibilidad que se demuestra de manera preclara en la siguiente frase:

"No podía, sin embargo, responder a las imágenes de los libros, a las descripciones que los arquitectos hacían de la ciudad americana, de una manera directa" (Rossi, 1984: 92).

$\mathrm{Su}$ 'formación americana' se sintetiza, por lo tanto, muy significativamente:

"Si tuviera que hablar de mi trabajo o de mi "formación" americana, me saldría demasiado de la autobiografía científica para introducirme en una autobiografía personal [contraposición o contraste] o en una geografía de mi experiencia, con lo cual me alejaría del tema principal de este libro. Tan solo quiero indicar que, en este país, las analogías, las referencias, las alusiones, lo que podríamos llamar observaciones, han provocado en mí un gran deseo creador y también, de nuevo, un importante interés por la arquitectura" (Rossi, 1984: 92).

Siguiendo en esta misma línea es obvio que recalca no hablar de sus 'fracasos' más que de un modo indirecto, 'fracasos' entrecomillados derivados de su obra construida -lo que él denomina 'algunas de mis desventuras'- y que trascienden solapadamente a ese 'olvido consciente y autorreconocido':

“Con tal observación a propósito de mi participación en un concurso no pretendo, en esta autobiografía de mis actividades, aludir a mis fracasos; tal vez deseo solamente señalarlos [como forma de intuirlos], pero no hablar de ellos. Mis más hermosos proyectos han sido, generalmente, rechazados en los concursos..." (Rossi, 1984: 60). ${ }^{23}$

23 Lo mismo ocurre con una de las actuaciones arquitectónicas más importantes a escala urbanística en las que Aldo Rossi ha intervenido, su actuación en los programas de regeneración urbana del IBA en Berlín durante la década de 1980, aspecto que se elude en la 'autobiografía...' como un 'olvido completo', que en este caso ni siquiera puede decirse que sea 'autorreconocido'. 
Con la intención de ir concluyendo este análisis de la Autobiografía científica de Aldo Rossi es posible ir, al mismo, tiempo determinando ciertas cuestiones no mencionadas hasta el momento y que corresponden quizás a inquietudes personales o justificaciones que el autor necesita mostrar, como puede ser, entre otras, el objeto y/o razón autobiográfica, ${ }^{24}$ el 'porqué' y el 'cómo' de la escritura de la 'autobiografía...', que constituye casi un 'acto voluntario de confesión':

"Si bien esta es hoy mi postura, y pese a que ninguna postura puede mantenerse siempre igual a sí misma, debo, no obstante, otorgarle un orden coincidente con esta autobiografía científica. Como he dicho, mi principal interés no era arquitectónico. Es interesante que mi primer artículo documentado llevase por título [regreso a los inicios de una germinante actividad intelectual] $\mathrm{La}$ coscienza di poter dirigere la natura. Se trata de un texto de 1954, es decir, de cuando tenía 23 años. Por otro lado, uno de mis escritos más importantes es de esa misma época. Se publicó en 1956, pero había sido compuesto el año anterior: alrededor de mis 24 años. Es el ensayo titulado II concetto di tradizione nell 'architettura neoclassica milanese" (Rossi, 1984: 51).

“...tal y como ocurre con este recorrido de mis proyectos, aunque no espero que de su análisis surjan ideas para mi redención o para la del oficio, sino tan solo las posibilidades de progreso que todo análisis supone" (Rossi, 1984: 54).

"En verdad, siempre he querido describir mis proyectos. [...] Esta autobiografía es el único modo en que puedo hablar de mis proyectos, aunque sé que ninguna de las dos cosas tiene importancia. Significa, quizás, el olvido de la arquitectura, y tal vez ya la olvidé al hablar de la ciudad análoga o cada vez que he repetido en este escrito que toda experiencia me parece definitiva y me resulta difícil determinar un antes y un después [reflexión autobiográfica y reiteración del 'olvido']" (Rossi, 1984: 68).

"La arquitectura de las sombras de Boullée o la búsqueda del lugar o locus de Palladio, no son simples autobiografías..." (Rossi, 1984: 93).

El origen autobiográfico se cita someramente:

“...imágenes de ciudad: Zurich, Berna, Friburgo, Colmar. Estas eran mis ciudades favoritas en los tiempos de profesor en Zurich, y, quizás, todo cuanto escribo pueda remontarse a un cuadernillo que titulé Quaderno di Colmar..." (Rossi, 1984: 55).

"Siempre he demostrado un especial interés por este sentido de la obra, y quizás ese sea también, en parte, el de estas notas" (Rossi, 1984: 87).

24 "Atenderá al plano discursivo o textual, en tanto que la autobiografía adopta la forma narrativa, y esto implica unas peculiares relaciones temporales entre el acto enunciativo, la narración propiamente dicha que tiene lugar en el presente, y lo narrado, que evoca sucesos del pasado. Se confrontan aquí los recuerdos, núcleos narrativos que constituyen la base de la historia protagonizada por yoes que ya no existen (el yo niño, el yo adolescente, cualquier otro yo del pasado), con las interpretaciones y con las conjeturas del narrador actual. La pluralidad de los distintos yoes que se ha sido queda contrastada en la memoria, y la continuidad (o la ruptura) entre aquellos yoes y el yo presente se establece en la escritura mediante el engarce entre la acción (la historia evocada, lo narrativo) y la introspección (el comentario, la valoración, lo expositivo)" (Fernández Prieto, 1997: 70). 
No son mucho mayores las especificaciones acerca de la circunstancia o momento, escenario temporal y vital, así como su ubicación espacial, en el que se encuentra cuando escribe la 'autobiografía...', un texto que ciertamente no tiene lugar concreto aunque el autor continuamente 'esté pensando -o imaginando- un lugar':

"Quizás tan solo en Nueva York, a lo largo del River Side, en donde estoy acabando, con los estudiantes del Instituto, un proyecto análogo..." (Rossi, 1984: 78).

Introduce también, el final de la autobiografía, en una especie de ‘comienzo del fin':

"Creo que ahora, las ideas de principio y final vuelven a ser importantes y a estar claras para mí. Tras mis primeras búsquedas, dirigidas hacia una refundación disciplinar, y este resultado, que supone la disolución o su olvido, existen estrechos vínculos. [...] Quizás el único defecto del fin y del principio es que son, en parte, un intermedio, es decir, que son previsibles. Y lo más previsible es, por supuesto, la muerte [idea ubicua que vuelve a estar omnipresente]" (Rossi, 1984: 98).

Se evidencian las líneas entrelazadas dedicadas a lo que convenimos en llamar 'homenajes' a otros escritores, artistas, arquitectos, filósofos y pensadores, figuras históricas y conocidas o simplemente gente cercana intelectualmente a su persona, lo cual muestra el interés de Rossi por hacer públicas sus referencias más relevantes, referencias de las cuales siempre se ha servido para la relectura o revisión de sus propias hipótesis:

“...la lectura, en mi primera juventud, del libro titulado Apparecchio alla morte, de Alfonso Dei Lugori. [...] Desde entonces ['hito' significativo] he visto en la arquitectura el instrumento que permite el acontecer de un hecho. He de decir que esa conciencia ha servido para aumentar, con los años, mi interés por el oficio, hasta el punto de que, en mis últimos proyectos, tan solo intento diseñar construcciones que, por decirlo así, preparen un acontecimiento. Más adelante hablaré de algunos de esos proyectos..." (Rossi, 1984: 14).

"Siempre me habían impresionado cuadros como II Natale dei remasti y Pio Albergo Trivulzio, de Angelo Morbelli: los observaba fascinado, sin poder juzgarlos. Ahora me servía de ellos como medios plásticos y figurativos, útiles para este proyecto. El estudio de las luces, los grandes rayos que caen sobre los bancos de los viejos, las precisas sombras de las figuras geométricas de esos mismos bancos y de la estufa, todo parecía extraído de un manual de teoría de las sombras" (Rossi, 1984: 23).

"Juan Serrano me regaló, en Córdoba, un libro fantástico que me resultó valiosísimo para entender, no la arquitectura cordobesa o andaluza, sino la estructura de la ciudad. El libro Paseos por Córdoba, no debe ser demasiado conocido..." (Rossi, 1984: 30).

"Los críticos deberían escribir libros como el que compuso el poeta americano Charles Olson sobre Melville; es uno de los más hermosos que conozco y sirve no sólo para conocer a Melville, sino a cualquiera dispuesto a emprender algo" .// El caso Melville resulta apasionante, porque en él veo con claridad [certidumbre] la relación que existe entre la observación y la memoria, o, si 
lo preferís, entre el análisis y la creatividad ['MEMORIA CREATIVA'] ${ }^{25}$ Del libro, que se titula Call me Ishmael..." (Rossi, 1984: 33).

"La descripción congelada de Loos se daba también en los grandes tratadistas, en las categorías de Alberti, en las cartas de Durero, y con ella desaparecía la práctica, el oficio, la técnica antes perseguida, porque, como en el origen, transmitir o traducir dejaban de tener importancia" (Rossi, 1984: 56).

"De todo esto ya me di cuenta en mis primeros años en el Politécnico. Es cierto que me gustaba el libro de Sigfried Giedion, ${ }^{26}$ en gran parte porque estaba ante todo basado en su entusiasmo por Le Corbusier, respecto a quien nunca me he pronunciado en sentido alguno. [...] Mi libro favorito era, sin duda, el de Adolf Loos, ${ }^{27}$ en cuya lectura y estudio me introdujo Ernesto N. Rogrs, a quien bien puedo llamar maestro; alrededor de 1959 leí a Adolf Loos por vez primera, en la bonita edición de Brenner Verlag. [...] Leía todo eso ingenuamente, pero, tal vez, era yo el único que lo hacía...” (Rossi, 1984: ).

"Por eso me han interesado especialmente, en los últimos años, los libros de inmunología. Llamó especialmente mi atención una definición de Ivan Roitt en su Essential immunology: "Memory, specificity, and the recognition of 'non-self' -these lie at the heart of immunology" (La memoria, la especificidad y la capacidad de reconocer estructuras químicas extrañas a la propia e individual constitución pueden ser considerados los aspectos peculiares de la dual inmunología). La memoria y la especificidad como elementos para reconocerse a sí mismo y reconocer lo extraño me parecieron las condiciones y explicaciones más evidentes de la realidad. No se da especificidad sin memoria, ni memoria que no provenga de la especificidad" (Rossi, 1984: 76-77).

Queda reconocer, en esta especie de 'homenaje a los citados', la importancia que algunos autores han tenido en su formación:

"Por otra parte, algunos de los autores aquí citados, sean o no arquitectos, llámense Conrad o Loos, han penetrado en mi vida, poseyéndola, y esa afinidad particular, o esa elección, aquello, en fin, que Baudelaire llamaba correspondances, forma parte de la propia formación y del modo de ser de

25 "La creación, [...] no puede ser arbitraria, sino que ha de resultar eficaz para algún propósito. Esto diferencia la creción de la extravagancia. [...] Gran parte del arte contemporáneo ha negado tozudamente que la creación tuviera que ver con la memoria. Una creencia generalizada y arbitraria identificó la memoria con la inercia psicológica. Para zafarse de esa inercia estéril, el arte trató de liberarse de la memoria mediante el repudio de la historia y la desacreditación de todas las técnicas establecidas. Los artistas admitieron como dogma de fe que la libertad no podía dejarse moldear por los hábitos sin suicidarse. Tenía que ser pura espontaneidad, surtidor de novedades, happening permanente. A la pregunta de si era posible una memoria creadora, respondiron con una negativa tajante. [...] La memoria, como inteligencia, se hace creadora cuando se integra en un proceso creador, en el que colabora con eficacia" (Marina, 1997: 48-49).

26 Acerca de la obra de este autor, por la importancia que ha tenido en la arquitectura, puede cotejarse:

- El presente eterno: los comienzos de la arquitectura, Madrid: Alianza Forma, 1992.

- Espacio, tiempo y arquitectura: el futuro de una nueva tradición, Barcelona: Científico-médica, 1968.

- Space, Time and Architecture: The Growth of a new tradition, Cambridge, Massachusetts: Harvard University Press, 1967.

27 Sobre la aportación más relevante de este autor véase la edición Ornamento y delito y otros escritos, Barcelona: Gustavo Gili ('Arquitectura y Crítica'), 1980. 
cada uno" (Rossi, 1984: 100).

Conjuntamente existe solamente en instantes muy puntuales cierta coralidad si es que se puede denominar así, con otras voces 'ajenas':

"José Charters me escribió diciendo que lo que más le había impresionado era, precisamente, esa arribada del teatro..." (Rossi, 1984: 81).

"Tony Vidler me regaló el libro de Frances Yates, Theatre of the World, con una bonita dedicatoria: "For A., from the theatre of the memory to the theatre of science"“ (Rossi, 1984: 85).

La coralidad 'directa' aparece, sin embargo, en ocasiones muy contadas, quizás en relación con el equipo de su estudio o sus colaboradores directos:

“...y cada cosa era tan sólo el inicio de lo que queríamos hacer...” (Rossi, 1984: 95).

Unido a ello se intuye la preocupación por la crítica (juicios externos que pueden ser negativos, neutros o positivos):

"A eso es debida la fama -digámoslo así- que durante mucho tiempo he tenido de germanista, y también el que la crítica relacionase mis trabajos con el mundo centroeuropeo" (Rossi, 1984: 58).

"Ha habido quien ha relacionado el interior del teatro con la luz de las pinturas de Carpaccio; no puedo transcribir aquí los juicios, en ocasiones muy hermosos, que los críticos han emitido acerca suyos: Tafuri, Portoghesi, Dal Co, Aymonino, Libeskind, y todos aquellos que se han interesado por esta construcción" (Rossi, 1984: 84).

"La autobiografía de la obra está contenida, ciertamente, solo en la misma obra, pero su descripción es un modo de hacerla transmisible, no demasiado distinto del proyecto o de la construcción [METALENGUAJE]. En los últimos años he leído muchas cosas sobre mi obra -a menudo muy extrañas y diferentes- y no puedo decir que haya aprendido demasiado con ello. Tan sólo que, en muchas ocasiones, las motivaciones son válidas pese a no coincidir con el pensamiento del autor" (Rossi, 1984: 87).

"Recuerdo ahora que algunos críticos han hablado de mis obras como de escenografías. [...] Con esto no pretendo defenderme de ninguna acusación, pero no comprendo cómo pueden condenarse mis obras por causas tan diferentes como, por un lado, su carácter escenográfico, y, por otro, por la supuesta pobreza de los medios expresivos que utilizan" (Rossi, 1984: 89).

“...pero lo que más me asombró fue ver cómo algunos críticos reducían el proyecto a una especie de experimento neoiluminista, lo cual debía ser consecuencia, más que de una intención crítica, del hecho de que fuera yo traductor de Boullée" (Rossi, 1984: 24).

Algunas de sus inquietudes se manifiestan con el arraigo a esa ‘teoría de las sombras', 
arquitectura de la 'penumbra' y del 'crepúsculo' ${ }^{28}$

"El tiempo de la arquitectura ya no se me aparecía con su doble naturaleza de luz y sombra [la dualidad de los opuestos], o como un envejecimiento de las cosas, sino como un tiempo de desastres que arraiga en ellas" . (Rossi, 1984: 27).

"Debo recordar la traducción de Etienne Louis Boullée y mi introducción a su libro. Alguna vez he sido acusado de infidelidad, incluso de haber inventado ese texto, lo que considero un cumplido. Debo admitir, sin embargo, que el resultado es compartido: por un lado, por la dificultad que representa la traducción del francés de Boullée, y, por otro, porque encontré en esa obra unas correspondencias que ya nunca he vuelto a experimentar. Es un trabajo del 67; cuando lo comencé tenía ya 35 años. No puede ser considerada, por tanto, como una obra de juventud. [...] A veces pienso en cómo obras de este tipo tan solo pueden darse en determinados momentos de la vida y cómo llegué a identificarme, en esa situación, con un antiguo académico francés..." (Rossi, 1984: 59).

Las citas literarias textuales que se ofrecen son también escasas cuantitativamente, hecho que se manifiesta conscientemente:

“A pesar de que en mi libro quiero reducir al máximo las citas...” (Rossi, 1984: $33)$.

"Intento utilizar pocas citas literarias, pero en ocasiones son precisas..." (Rossi, 1984: 61).

Un fenómeno peculiar en este sentido constituye la única cita textual -ciertamente amplia, quizás sea la más extensa de toda la 'autobiografía...'-, que realiza de un extracto de sus propias anotaciones, captando del entorno referencias para sus obras de arquitectura. Rossi dice así al introducir sus propias palabras:

\footnotetext{
28 En el Cenotafio a Newton de Boullée por ejemplo (fig.5), "pensado para un material de textura áspera que recogiera la luz, la presencia minimalista de la forma total, apenas se alteraba con dos hileras de flores y árboles en recuerdo de los homenajes de los antiguos a sus difuntos. En el interior también se sometía a la austeridad formal; el amueblamiento básico era el sarcófago, emplazado en el centro gravitacional del edificio, y la captación emocional del lugar descansaba, nuevamente, en los efectos producidos por el control de la luz y el espacio". (Arnaiz, 1995: 159). Esa misma luz con la que se pretendían crear simulaciones del día y simulaciones de la noche, puesto que por el día el interior de la esfera permanecía a oscuras con unas leves incisiones por donde penetraba la luz del exterior creando el efecto de una noche despejada con firmamento estrellado. En horas crepusculares en cambio, se pretendía que la esfera iluminase irradiando luz hacia el exterior simulando un gran sol. Boulleé se interesa por las estructuras de fábrica cerrada donde la luz es siempre cenital, pues la idea de la apertura del muro es poco menos que temeraria. La autora mencionada recupera lo sublime y el 'lado oscuro' de esta 'arquitectura de las sombras' apoyada en los efectos simulácricos de la luz que hemos mencionado en contraste con la materia y las volumetrías. En este contexto los edificios que proyecta Boulleé son 'proclamas de la arquitectura' para el profesor y arquitecto Alberto Ustárroz -al igual que para A. Rossi- y es significativo el hecho de que casi nunca aparecen integrados en un entorno urbano, sino que se representan aislados y rodeados de bosque o elementos naturales de vegetación. El monumento cumple en este momento de las utopías ilustradas la función de "memoria y conmemoración de lo individual (el genio de Newton); y, a la vez, no olvida lo colectivo, transcendiendo en un homenaje 'sublime' al reino del conocimiento de la naturaleza como sustituto definitivo del orden divino". Ibíd.
} 
"Quiero transcribir aquí una breve descripción de la catedral de Milán que escribí en uno de mis cuadernos azules. Es de 1971 [fecha que marca, como se ha visto en múltiples ocasiones, el inicio de las notas autobiográficas], y a menudo pienso que se trata de un proyecto mío, o quizás lo sea efectivamente, de igual modo que todas las obras que vivimos son nuestras obras [retoma la actitud vital comprometida con la arquitectura]" (Rossi, 1984: 74).

Transcribimos aquí dicho párrafo ya que consideramos significativo ofrecer este documento del escrito manuscrito de Rossi:

"Notable experiencia de la arquitectura de la catedral de Milán [vuelve a revelarse la importancia de la arquitectura religiosa], a la que hacia mucho tiempo que no subía. Tiene relación con el tema de la alineación de los elementos y, naturalmente, con la verticalidad. Al salir de la escalera se recorre un largo pasillo al descubierto. El pasillo atraviesa los arbotantes mediante estrechas puertas que se suceden según el ritmo de los arcos. Los arbotantes, con gárgolas en sus extremos, sirven para desaguar la cubierta, casi plana. La planta de la cubierta es como una pequeña plaza de piedra. Estudiar la dimensión de la piedra. A los lados, la dimensión de la arquitectura viene dada por los contrafuertes, que caen a plomo, y por el basamento. El basamento es un notable ejemplo de contaminatio en arquitectura, y no puede encontrarse en ningún otro edificio gótico. (En realidad, en esta obra se demuestra la insuficiencia de toda clasificación estilística). En esencia, no se diferencia demasiado de los estilóbatos que rodean el templo de Fortuna Virilis, el de Augusto en Nimes y Pola, y tantos otros. (Rocco, notas sobre los orígenes de la catedral). Los contrafuertes constituyen una sucesión regular. Aparecen paralelepípedos que cortan normalmente el costado. Los contrafuertes se apoyan sobre el basamento continuo. La intervención de Pellegrini en la fachada es increíble: la solución está en la dimensión de las puertas y en la concitación de los elementos encerrados. Sólo tal concitación podría relacionarse de alguna manera con la multitud de elementos de la catedral. En la fachada, durante las fiestas religiosas, se cuelgan cuadros y adornos rojos y azules" (Rossi, 1984: 74).

Se pueden entresacar finalmente unas breves referencias estilísticas que llaman la atención por su curiosidad, siendo uno de estos detalles la 'supresión' de algunos nombres de lugares o de personas, citándolos únicamente por su inicial en mayúsculas, en una especie de estrategia que esboza un espacio liminal o fronterizo, entre 'la memoria en proceso de desintegración, de olvido', y el 'olvido consciente' que decíamos recuperando tímidamente vagos 'recuerdos' en ocasiones baldíos: “...junto al lago de M. [p.20]” ; “...situado en la carretera, junto a S. [p.37]” ; “...viejo oratorio transcrito para mí por P. [p.56]” son algunos de los ejemplos de ese 'deslizamiento' en el que los lugares o personas se nombran de este modo tan singular. Si hablamos de 'estilo' no se puede obviar por fin el 'Estilo en arquitectura' de Aldo Rossi (adelantándose así a cierto 'revisionismo' en arquitectura), siempre enfocado también en ese 'límite' que bascula, tal y como se puede apreciar, al abrigo de los últimos clásicos, los primeros modernos y los embrionarios postmodernos:

"Pero eso no tiene para mí ninguna importancia; creo que queda claro mi consideración sobre la posibilidad de toda técnica, hasta el extremo de atreverme a llamarla estilo" (Rossi, 1984: 89). 

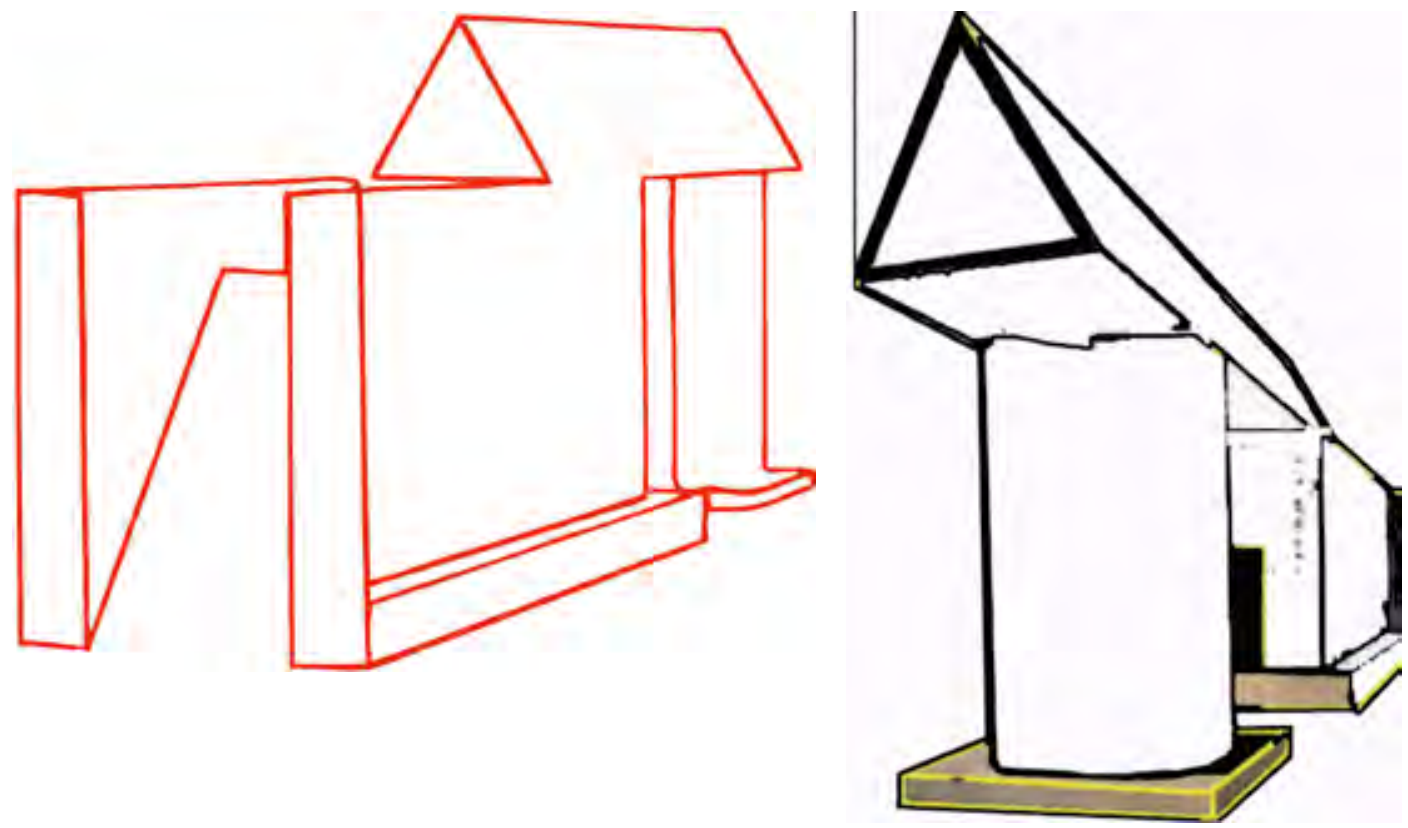

Fig.2. Cementerio de Módena, Aldo Rossi

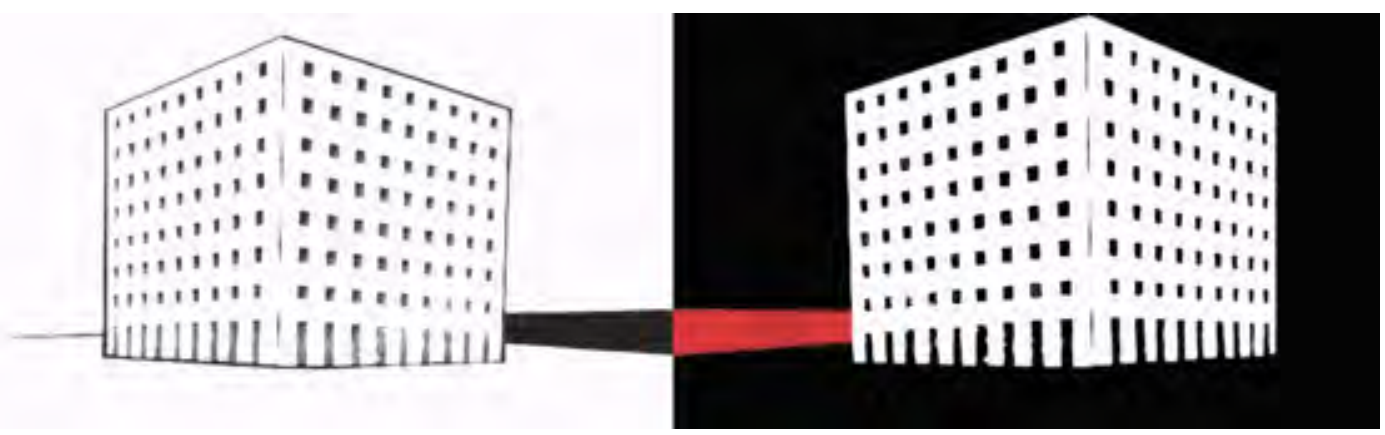

Fig.3. Monumento a Segarte. Aldo Rossi, 1965.

\section{Tercera parte. Aproximaciones conclusivas}

"Las cosas no están en los documentos sino en la forma que tenemos de relacionarlos" (Tonia Raquejo).

Hemos de retomar ahora como aproximación conclusiva de este estudio, el decisivo compromiso que continuamente Aldo Rossi muestra con la arquitectura, con el oficio, con la actividad profesional; compromiso vitalmente concatenado con un itinerario personal a la vez que científico, tal y como reseñaba en las primeras líneas del prólogo de este texto a propósito del título propuesto. La arquitectura se convierte así poco menos que en metáfora de la propia vida en A. Rossi, memoria de 'vida y obra' que se refleja y se detecta en los hitos que establecen el recuerdo de los sucesos que han acontecido (recuerdos a veces colaterales que sirven para la estructuración de la autobiografía en torno a las áreas temáticas), ocultándose sin embargo en esos otros 'huecos vacíos' y silencios, discontinuidades, síntomas de olvido consciente -'procesos de silenciamiento' a veces contradictorios que únicamente dan lugar a hipótesis sin que existan relaciones causa/ efecto- u olvidos inconscientes en la 
narración como hechos confusos e inaccesibles a la espera de que se descifren aunque fuera implícitamente. La historia que A. Rossi presenta es así la historia de cómo él entiende la arquitectura, tal que proclamas rescatadas del olvido y repletas de subjetividades. La inquietud personal en este caso se articula en torno a un quehacer colectivo pero siempre bajo una mirada interior que produce reflexión y que conecta con el exterior, captando a través del relato verbal la gran profundidad de la experiencia que una disciplina conlleva (en este caso la arquitectura, conjuntamente con al bagaje disciplinario del cual no es posible abstraerse).

La fuerza del poder evocador, extremadamente versátil y cambiante, asoma para A. Rossi en imágenes y fotografías, que aluden a sensaciones de infancia y arquitectura sobre todo religiosa ${ }^{29}$. La evocación, esa herramienta metodológica del recuerdo que explicita las dimensiones de la memoria, produce idas y venidas temporales en una relación simbólica del presente con el pasado e incluso con el 'vacío del futuro', puesto que hay que recordar que para Rossi 'los grandes hechos han prescrito históricamente', de modo que la posible memoria del futuro que de ello deriva -’ ¿a qué podría aspirar en mi oficio?'- no es demasiado halagüeña por lo que el proyecto en ocasiones aparece como ensoñación (el futuro no es vivido, sino que es especulativo y próximo a la 'nada', al gran abismo del 'vacío'). Abismo que se configura con la intuición de la llegaba de una postmodernidad difusa e inerte, tras la crítica a las generaciones anteriores de arquitectos que suscitaron ciertas esperanzas de 'redención'; los modernos que 'defraudaron', que son en este caso los grandes 'ausentes' cuya presencia se pone de manifiesto precisamente con la negativa a mencionarlos. Otros ausentes, los colegas (las personas que se introducen así en un contexto más o menos íntimo), se hacen presentes mediante sus iniciales, al igual que algunos lugares, como si el recuerdo se difuminase en la memoria antes de, siquiera, poder ser escrito, o quizás porque a las palabras escritas nunca se las lleva el viento...

Decíamos que A. Rossi ve la arquitectura como metáfora de la vida; metáfora que se establece quizás por medio de visiones paralelas de ciudades en La arquitectura de la ciudad (su gran contribución teórica), donde se integran los 'hechos urbanos' y las 'permanencias'. La clave de ello nos la proporciona Alan Lightman cuando en uno de los pasajes de Sueños de Einsten interpone la ciudad como metáfora de la vida utilizando la siguiente analogía: "partes de la ciudad se quedan adheridas a algún momento de la historia y no se pueden desprender. Y también las personas se quedan pegadas a algún momento de sus vidas y no pueden liberarse" (Lightman, 1993: 56) ${ }^{30}$ La construcción/creación de la ciudad en el tiempo estratificadamente, produce sedimentos de memoria. Memoria pasada por la experiencia y entremezclada con la memoria del propio cuerpo materializada para Rossi en el 'dolor de huesos'; el cuerpo, es como la arquitectura, al igual que la arquitectura y la idea de ciudad ha sido en ocasiones asimilada a un órgano que integra diversas funciones y genera sinergias y/o movimientos en infinidad de direcciones. Por último, quisiéramos introducir para concluir una cuestión que vamos a dejar abierta, si es que, de algún modo ¿sería posible contar o narrar de la misma manera una autobiografía científica que una personal?, ¿y si lo científico, o el oficio, es lo que abona el campo de lo personal, como se puede suponer en este caso, constituyendo un todo unísono sin solución de continuidad? Estas interrogantes más bien retóricas esperamos que algún día encuentren alguna respuesta, personal acaso, en las conciencias de los lectores y también, por qué no, en las mentes de los propios escritores/ as de autobiografías.

29 Las fotografías pueden ser trazos de memorias personales, por ejemplo la búsqueda de la identidad en Blade Runner. Y nos preguntamos con Matteo Manfredi, en ese sentido, si es que podemos hablar, acaso, de 'autobiografías fotográficas'.

30 La ciudad como 'pieza' que forma un todo, se contradice con la imagen fragmentaria múltiples que cada una de ellas 'se ajusta a un tiempo diferente', recordando la visión de la ciudad de Baudelaire en la que los campanarios góticos sobresalían junto a las 'arquitecturas de hierro' de la modernidad. 
En este sentido, B. Sarabia (1985: 173) recuerda que "con frecuencia una vida, una biografía por consiguiente, se construye entre personas y se sostiene en una estructura social". Evidentemente, en esa 'estructura social' no se incluyen únicamente los 'relatos' personales sino también los profesionales. En cualquier caso, hemos de tener muy en cuenta siguiendo a Mario L. Rodríguez que cualquier autobiografía, cualquier relato sobre la propia vida (que aparece como lo más indubitable, inmediato y conocido para uno mismo), sufre innegables distorsiones y alejamientos de los hechos que ocurrieron. Esto partiendo de la premisa de que estamos dejando de lado todo trazo de mala fe, si esto es posible, suponiendo que el mencionado relato es sobre uno mismo (auto-biográfico). Bien podríamos apoyarnos en un 'diario' personal y al releerlo constatar que: 1 . Los 'hechos' escritos casi en el mismo momento de ocurrir fueron enfatizados en ciertos nudos significantes para aquel momento pero irrelevantes para el momento actual (el autor podría ahora pensar que debería haber consignado otros aspectos y que de rescribir su 'diario' lo haría de manera muy diferente); 2. Que la descripción tiene carácter de reelaboración de lo ocurrido como estructuración de una perspectiva temporal diferente de la actual; 3. Que las valorizaciones de los hechos corresponden a una escala muy diferente a la de este momento; 4. Que variados y, a veces, compulsivos fenómenos psicológicos apoyados en el pretexto del relato, han teñido fuertemente las descripciones al punto de avergonzar hoy al lector por el autor que éste fue (por la candidez, o la perspicacia forzada, o la alabanza desmedida, o la crítica injustificada, etc.). Y así hay una quinta y sexta y séptima consideración que hacer respecto a la deformación del hecho histórico personal, ¿qué no habrá de ocurrir entonces a la hora de describir hechos históricos (no vividos por nosotros), previamente interpretados por otros? De esta suerte, la reflexión histórica se hace desde la perspectiva del momento histórico del que reflexiona y con ello se vuelve al suceso modificándolo. En todo caso y desde nuestro punto de vista, no podemos dejar de observar que:

"Recoger formación mediante el relato de vida supone aplicar una herramienta metodológica concreta. [...] La expresión 'relato de vida' se introduce en Francia, a mediados de la década de los setenta del pasado siglo veinte, de la mano de Daniel Bertaux (1980: 198-225). Hasta ese momento el término consagrado en las ciencias sociales era el de 'historias de vida': pero este término tenía el inconveniente de no distinguir entre la 'historia' vivida por una persona y el relato que ella podrá hacer de esa historia a petición de una persona investigadora. [...] Trabajar con historias de vida no es únicamente recoger itinerarios biográficos personales o comunitarios, hechos vividos o representaciones mentales, que corresponden a una vida, es mucho más. [...] Para ello es necesario el trabajo de la persona investigadora, que ha de aplicar una actitud metodológica, dentro de la relación de intersubjetividad que se produce en la recogida de información, además de su 'intención' teórica [...], partiendo del principio de que recogemos información biográfica $\mathrm{y}$, sin embargo, producimos el dato" (García Orellán, 2012: 177-212).

La evocación, aunque esta pueda ser más entrecomilladamente 'científica' o profesional que personal, "también puede erigirse en una herramienta metodológica para explorar el pasado, tanto en el proceso autobiográfico como en la elicitación del recuerdo en la biografía [...]. La evocación es altamente cualitativa, y en muchos casos está preñada de emociones sutiles. En el proceso autobiográfico juega un papel central" (Del Valle, 2012: 303-311). 
ANEXO: Aldo Rossi. Breve reseña biográfica

"Sus pensamientos van de su obsesión por el teatro a su idea de arquitectura como ritual; de su encuentro con la muerte en proyecto del cementerio de Modena, a su búsqueda de la felicidad en el proyecto de la residencia de estudiantes de Chieti" (Kurt Foster).

El arquitecto milanés Aldo Rossi (1931-1997), es, como versa la editorial de una de las recopilaciones más importantes de su obra arquitectónica, "uno de los creadores del mundo de la cultura y de la arquitectura que, al haber elaborado una metodología propia, ha alcanzado amplia repercusión internacional y es objeto de estudio por parte de las generaciones actuales" (AA. VV., 1986: s/p). Formado en su origen en el Politécnico de Milán (período académico 1949-1956), no tardará en suscitar controversias acerca de sus ideas tanto personales como profesionales en cuanto se traslada a Praga y posteriormente a la Unión Soviética en 1955, por razones de estudios e intercambios culturales, así como seguidamente cuando se gestan sus primeros escritos desde las páginas de la revista Voce comunista, y es invitado por Hans Schmidt, entonces director de la Academia de la Construcción Alemana en Berlín -Deutsche Bauakademie-, a visitar la RDA. Curiosamente, al contrario que en el caso de la URSS., Berlín volverá a reclamar su atención ya en la edad madura regresando una vez más a esa misma ciudad, sin par escenario para la arquitectura. Lograda la titulación oficial correspondiente de arquitecto en 1956, comienza a trabajar con Ignazio Gardella y Marco Zanuso en la primera época, colaborando fundamentalmente en el montaje de exposiciones, lo cual le será de utilidad en su desarrollo posterior de cara a la participación en las exposiciones de arquitectura celebradas en Italia y en el extranjero.

Su carrera docente tiene como punto de partida inicial su país natal -concretamente la Escuela de Urbanismo de Arezzo-, como adjunto del entonces profesor titular Ludovico Quaroni, y de Carlo Aymonino en el Instituto Universitario de Arquitectura de Venecia, donde por cierto concluirá tiempo después, la labor docente casi en el ocaso de su vida. En 1965 entra a formar parte de la plantilla del Politécnico de Milán, haciéndose patente la polémica que le acompaña también en la docencia puesto que en 1971, junto con dos miembros más de la Facultad de Milán, se le prohibe impartir clases en Italia 'por su 'dudosa' o 'sospechosa' "actividad político - cultural" en la Universidad'. Estos últimos cinco años son cruciales para Aldo Rossi, dado que, tal y como hemos constatado en el análisis de la Autobiografía científica, primeramente en 1966 ve la luz su contribución teórica más importante: La arquitectura de la ciudad ('L'architettura della città'), ${ }^{31}$ y correlativamente un lustro después, en 1971, es cuando finaliza el proyecto para el concurso del cementerio de Módena con la colaboración de Gianni Braghieri, otro de los hitos más importantes e incluso 'trascendentes' a lo largo de su vida ('encuentro con la muerte'). Al año siguiente es llamado por el Politécnico Federal de Zurich para impartir clases como profesor de proyectos, lugar que ocupará durante tres años. Quizás tocado directamente por la influencia germana, en 1973 realiza su único film titulado: "Ornamento y delito", en homenaje e uno de sus más queridos y apreciados maestros, el arquitecto Adolf Loos, al cual alude repetidamente en la 'autobiografía...'.

A pesar de que en 1975 es readmitido como profesor en Italia, no volverá al Politécnico de Milán, cuna de su formación, y es entonces cuando inicia su periplo en tierras americanas, contribuyendo amablemente a las diversas exposiciones de su obra arquitectónica, al mismo tiempo que comienza la 'ruta docente' en las universidades americanas -básicamente en EE.UU.- (Cooper Union e Institute for Architecture and Urban Studies de Nueva York, Harvard, Ithaca, Yale), aparte de sus estancias en Sudamérica (Buenos Aires), Europa, Asia y Japón ya en 1984, invitado por las autoridades e instituciones culturales niponas. Tres

31 Ver bibliografía (las correspondientes ediciones y su prolongación temporal). 
años antes, en 1981, aparecería publicada por vez primera su Autobiografía científica ('A Scientific Autobiography') ${ }^{32}$ por parte de la Universidad de Harvard, el mismo año que como adelantábamos anteriormente, obtiene el primer premio -con G. Braghieri, C. Stead y J. Johnson- en el Concurso Internacional restringido "Internationale Bauausstellung (IBA) Kochstrasse/ Friedlichstrasse, Berlín 1984", dentro del programa de la regeneración berlinesa (hecho importante que sin embargo no se cita en la 'autobiografía...'), uno de cuyos mayores artífices será el arquitecto Josef Paul Kleihues. Ya avanzábamos que sin duda entre sus proyectos más relevantes se encuentra el camposanto de San Cataldo en Módena (primer y segundo grado). No obstante en la 'autobiografía...' remarca también los trabajos para el Monumento de la Resistencia en Cuneo (1962 -conjuntamente con L. Meda y G. U. Polesello-), la residencia estudiantil en Chieti (1976), el "Teatro Científico" (1978) y el "Teatro del Mundo" (1979) en Venecia (ambos con G. Braghieri y R. Reno), denotando su 'obsesión por el teatro'. En el plano arquitectónico, atendiendo a su obra proyectada y/o construida es de constatar que el equipo de Aldo Rossi contribuye, siguiendo su actitud de 'investigador de la ciudad', en la redacción, mediación y elaboración en la medida de lo posible de numerosas figuras de planeamiento, ordenación territorial y planes urbanísticos además de las construcciones y concursos puntuales predeterminados.

Respecto a la vertiente teórica e investigadora se ha de señalar que "los escritos de Rossi están íntimamente ligados a sus dibujos y a sus proyectos arquitectónicos" (Rossi, 1984: 127) tal y como se deriva del análisis autobiográfico. Si bien sobresale más en cuanto a calidad que a cantidad si nos referimos a sus escasos libros y tratados,${ }^{33}$ no así como articulista, con una obra extensa y prolífica en colaboraciones; prólogos, capítulos, recensiones y compilaciones, actas de jornadas, congresos, coloquios y seminarios impartidos, ponencias y comunicaciones a congresos, entrevistas realizadas...etc. La mayor parte de los escritos se han editado en: Scritti scelti sull'architettura e la città: $1956-1972,{ }^{34}$ con las temáticas propias que sirven de encabezamiento a la recopilación. Auspiciado por el reconocimiento internacional de su trayectoria profesional, investigadora y académica A. Rossi es galardonado con el premio Pritzker en 1990, I’AIA Honor Award en 1991 y Jeferson Memorial Award en 1992. Recibe el reconocimiento del Consejo de Ministros de Italia a propuesta de la Comisión de Cultura de la Presidencia con un Premio Especial de Cultura en 1996, siendo nombrado miembro honorario del American Academy of Arts and Letters en 1997, casi al final de su vida.

\section{Bibliografía.}

Observaciones: Esta bibliografía refleja los libros y escritos más importantes del arquitecto Aldo Rossi, recogiendo obras en las que ha colaborado presentando artículos, prólogos y capítulos, con la intención de proporcionar ciertas referencias acerca de los parámetros que se vislumbran en la tarea investigadora del autor, de cara a una mejor y más correcta interpretación de su 'autobiobiografía científica' que en estas páginas se presenta. Se citan así mismo publicaciones referentes a su trayectoria profesional y aportaciones que posteriormente se han realizado complementando las teorías de Aldo Rossi. No se han incluido, sin embargo, reseñas en catálogos de proyectos arquitectónicos concretos o puntualmente determinados. Así mismo, se incluyen otras fuentes documentales y bibliográficas utilizadas en la elaboración del texto.

\section{Escritos y colaboraciones de Aldo Rossi:}

BONICALZI, Rosaldo (dir.)

1989 Scritti scelti sull'architettura e la città 1956-1972, Milano: Clup.

32 Puede cotejarse la bibliografía adyacente.

33 A Rossi se le conoce también como traductor y prologuista de Boullée: "Introduzione a Boullée", en: Etienne Louis Boullée, Architettura saggio sull'arte, versión italiana de Aldo Rossi, Padua 1967, pp.7-24.

34 Véase la bibliografía que se adjunta. 

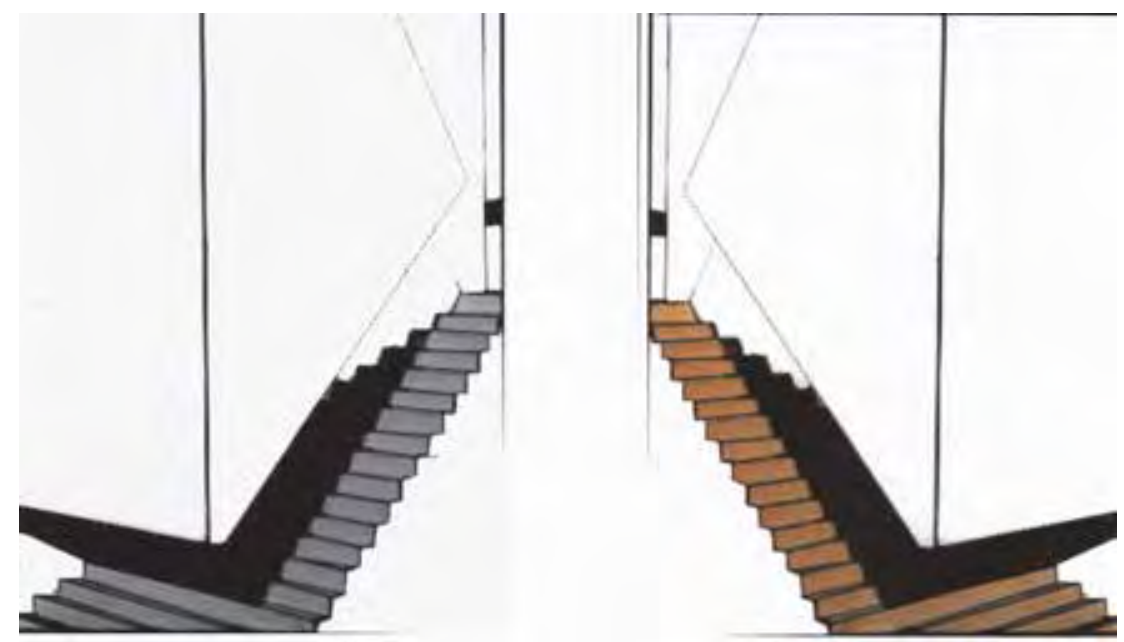

Fig.4. Monumento a la Resistencia Partisana en Cuneo. Aldo Rossi, 1962.

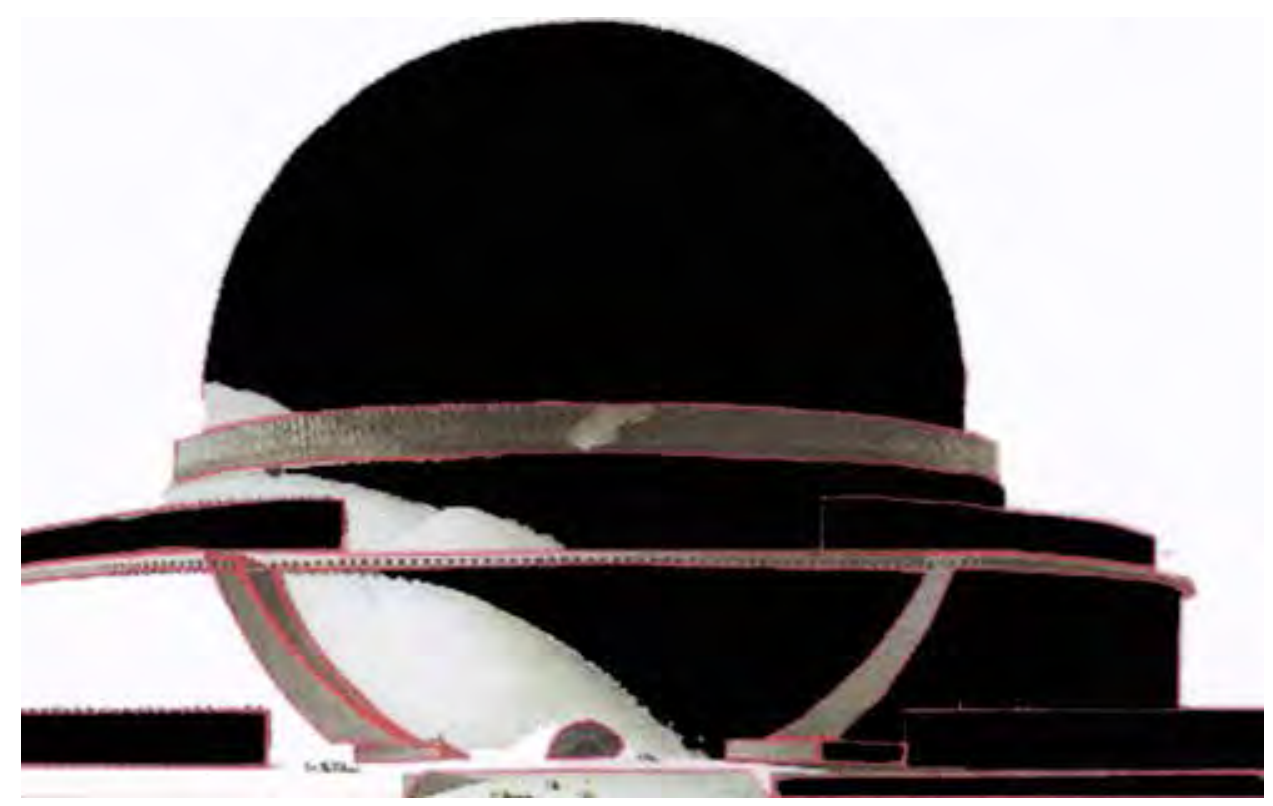

Fig.5. Cenotafio a Newton. Etienne L. Boullée, 1784. Original: BIBLIOTECA NACIONAL DE PARÍS.

CANTÁFORA, A.; CORTESESI, G.; ROSSI, A. (et al.)

1988 Architetture dipinte, Milano: Electa ('Documenti di Architettura'-31).

JIMENEZ, C.; FOSTER, K. (prolog.); ROSSI, A. (prolog.)

1991 Carlos Jiménez, Barcelona: Gustavo Gili ('Catálogos de Arquitec. Contemporánea').

HUET, Bernard (colab.)/ LOMBARDO Patrizia (comp.)

1984 Tre città=three cities: Perugia, Milano, Mantona, Milano: Electa ('Quaderni di Lotus'-4).

LOOS, Adolf; ROSSI, Aldo (prolog.)

1981 La civiltà occidentale: “Das Anderes” et altri scriti, Bologna: Zanichelli.

PÉROUSE DE MONTILOS, Jean-Marie (ed. lit.)

1968 Architecture essai sur l'art, Paris: Hermann.

ROSSI, Aldo (prologuista)

1981 Architettura saggio sull arte, Padova: Marsilio. 
ROSSI, Aldo

1984, 1994 (reprints) Autobiografía científica Barcelona: Gustavo Gili.

ROSSI, Aldo

1999 De Dante a Leonardo: un percorso di originali Firenze: Sismel (Biblioteche e Archivi). ROSSI, Aldo

1976, 1981, 1986, 1992, 1995 La arquitectura de la ciudad, Barcelona: Gustavo Gili.

ROSSI, Aldo; VITALE, Daniele (ed.)

1987 (reed.)* architettura della città, Milano: Clup-cittàstudi.

ROSSI, Aldo

1981 Scientific Autobiography, Cambridge, Massachusetts: The Institute For Architecture And Urban Studies, The Massachusetts Institute Of Technology, The MIT Press.

* Primera edición italiana: 1965-66. Segunda edición con nuevo prefacio en 1969-1970. Tercera edición, también en italiano: 1973. Cuarta edición: 1978 (en español, alemán, portugués y posteriormente en inglés).

\section{Publicaciones acerca de la actividad profesional e investigadora de Aldo Rossi:}

AA. VV.

$1981 \quad$ Aldo Rossi and 21 works, Tokyo: A+U.

ADJMI, Morris (ed.); GHIRDO, Diane (colab.); ROSSI, Aldo; STEIN, Karen (colab.)

1991 Aldo Rossi: The complete buildings and projects, London: Thames \& Hudson.

ARNELL, Peter (coed.); BICKFORD, Ted (coed.); ROSSI, Aldo (coaut.)

1986 Aldo Rossi: obras y proyectos, Barcelona: Gustavo Gili.

AYMONIO, Carlo; FUTAGAWA, Yukio (ed. lit.); NICOLIN, Pierluigi (colab.); ROSSI, Aldo (coaut.)

1977 Carlo Aymonio, Aldo Rossi: Housing Complex at the Gallarastese Quarter Tokyo: ADA ('Global Architecture'-45).

BRAGHIERI, Gianni

1986 Aldo Rossi, Barcelona: Gustavo Gili ('Estudio/paperback').

FERENGA, Alberto (ed.); ROSSI, Aldo (et. al.)

1987 Aldo Rossi: architettura 1959-1987, Milano: Electa.

FERENGA, Alberto; ROSSI, Aldo

1992 Aldo Rossi: architettura 1988-1992, Milano: Electa.

FERENGA, Alberto; ROSSI, Aldo

2001 Aldo Rossi: the life and works of an architect, Cologne: Kröneman.

MONEO; SCULLY; VINCENT

1986 A. Rossi. Obras y proyectos, Barcelona: Gustavo Gili.

ROSSI, Aldo

1999 Aldo Rossi: disegni 1990-1997, Milano: Federico Motta ('Mota Architettura').

SAVI, Vittorio; ROSSI, Aldo (coaut.)

1981 L'architettura di Aldo Rossi, Milano: Franco Angeli ('Collana di Architettura'-7).

\section{Aportaciones posteriores a la actividad teórica e investigadora de Aldo Rossi:}

LUQUE VALDIVIA, José

1996 La ciudad de la arquitectura. Una relectura de Aldo Rossi, Barcelona: Oikos-Tau ('Colección de Urbanismo').

SAINZ GUTIERREZ, Victoriano

1999 La cultura urbana de la postmodernidad. A. Rossi y su contexto, Sevilla: Alfar.

\section{Otras fuentes documentales y bibliografía utilizada:}

ARNAIZ, Ana

1995 La memoria evocada. Vista Alegre, un cementerio para Bilbao (tesis doctoral), Bilbao: Servicio Editorial de la Universidad del País Vasco/ EHU. 
BLANCO, Amalio

1997 "Los afluentes del recuerdo: la memoria colectiva", en: AA. VV., Claves de la memoria, Madrid: Trotta.

BERTAUX, D.

1980 «L'approche biographique, sa validité méthodologique ses potentialités», in: Cahiers Internationaux de Sociologie, LXIX, pp.198-225.

DEL VALLE, Teresa

2012 "El poder evocador como desencadenante de memoria y creatividad", en: Pels camins de l'etnografia: un homenarge a Joan Prat, Tarragona: URV, pp.303-311.

FERNÁNDEZ PRIETO, Celia

1997 "Figuraciones de la memoria en la autobiografía", en: en: AA. VV., Claves de la memoria, Madrid: Trotta.

GARCÍA ORELLÁN, Rosa

2012 "Patrimonio inmaterial e historia oral en torno a la pesca industrial. Imaginarios del pasado siglo XX", en: Zainak 35 (Cuadernos de Antropología-Etnografía), Eusko Ikaskuntza/ Sociedad de Estudios Vascos, pp. 177-212.

LIGHTMAN, Alan

1993 Sueños de Einstein, Barcelona: Tusquets, (edición original en inglés, 1992).

LYNCH, Kevin

1984 La imagen de la ciudad, Barcelona: Gustavo Gili ('Colección Punto y Línea').

MARINA, José Antonio

1997 "La memoria creadora", en: AA. VV., Claves de la memoria, Madrid: Trotta.

MUÑOZ MOLINA, Antonio

1997 "Memoria y ficción", en: AA. VV., Claves de la memoria, Madrid: Trotta.

SARABIA, B.

1985 "Historias de vida", en: REIS, n 29, Madrid.

UMBRAL, Francisco

1974 Las Europeas, Barcelona: G. P. Extracto citado por: MARINA, José Antonio, "La memoria creadora", en: AA. VV., Claves de la memoria, Madrid: Trotta, 1997. 